\title{
MORFOLOGIA, BIOLOGIA E FOTOTROPISMO DE BATRACHEDRA NUCIFERAE HODGES (LEPIDOPTERA: COLEOPHORIDAE)
}

\section{SAÚL SÁNCHEZ SOTO}

\author{
Tese apresentada à Escola Superior de \\ Agricultura "Luiz de Queiroz”, Universidade \\ de São Paulo, para obtenção do título de \\ Doutor em Ciências, Área de Concentração: \\ Entomologia.
}

P I R A C I C A B A

Estado de São Paulo - Brasil

Janeiro - 2004 


\section{MORFOLOGIA, BIOLOGIA E FOTOTROPISMO DE BATRACHEDRA NUCIFERAE HODGES (LEPIDOPTERA: COLEOPHORIDAE)}

\section{SAÚL SÁNCHEZ SOTO}

Biólogo

Orientador: Prof. Dr. OCTAVIO NAKANO

Tese apresentada à Escola Superior de Agricultura “Luiz de Queiroz”, Universidade de São Paulo, para obtenção do título de Doutor em Ciências, Área de Concentração: Entomologia.

P I R A C I C A B A

Estado de São Paulo - Brasil

Janeiro - 2004 
Dados Internacionais de Cat alogaçã o na Publicaçã o (CIP) DIVISÃ O DE BIBLIOTECA E DOCUMENTAÇÃ O - ESALQ/USP

\section{Sánchez-Soto, Saúl}

Morfologia, biologia e fototropismo de Batrachedra nuciferae Hodges

(Lepidoptera: Coleophoridae) / Saúl Sánchez Soto. - - Piracicaba, 2003.

40 p. : il.

Tese (doutorado) - - Escola Superior de Agricultura Luiz de Queiroz, 2004.

Bibliografia.

1. Biologia animal 2. Fototropismo 3. Inseto nocivo 4. Morfologia animal 5.

Traça do coqueiro I. Título

CDD 632.7

"Permitida a cópia total ou parcial deste documento, desde que citada a fonte - O autor" 
Dedico este trabalho à minha família, parentes e amigos, especialmente aos:

meus pais Tito Sánchez e Aurea Soto; minha esposa Nury; aos nossos filhos Wendy, Saúl e Nury;

à minha tia María Sánchez (in memoriam)

e à minha sogra Trinidad Gómez (in memoriam) 


\section{AGRADECIMENTOS}

A Deus, pela vida, saúde e proteção;

Ao Prof. Dr. Octavio Nakano, pela confiança, ensinamentos, amizade e excelente orientação;

À Universidade de São Paulo (USP), especialmente ao Departamento de Entomologia, Fitopatologia e Zoologia Agrícola da Escola Superior de Agricultura "Luiz de Queiroz" (ESALQ), pelo acolhimento e ensinamentos recebidos através dos meus Professores: Dr. Octavio Nakano, Dr. Celso Omoto, Dr. José Roberto Postali Parra, Dr. Roberto Antonio Zucchi e Dr. Evoneo Berti Filho;

Ao Programa Nacional de Superación del Personal Académico, Asociación Nacional de Universidades e Instituciones de Educación Superior (ANUIES) - México, pela bolsa de estudos concedida;

Ao Colegio de Postgraduados - México, pelo apoio financeiro; especialmente à memória do Dr. David Riestra Diaz, ex - Director del Campus Tabasco, pelos apoios concedidos;

Ao Dr. Eugenio Carrillo Ávila, do Colegio de Postgraduados, pela confiança e ajuda em relação à parte financeira;

Ao Ing. Carlos Alves Pereira e Ing. Augusto de Morais D’Elia, de Araçatuba, São Paulo, pela amizade e ajuda na obtenção de material biológico; 
Ao Prof. Dr. Sinval Silveira Neto, do Setor de Entomologia, ESALQ/USP, pela amizade e fornecimento de material utilizado;

A Patrícia Milano pela amizade e realização dos desenhos; e a Heraldo Negri, pelo apoio com algumas fotografias;

À Sra. Márcia Saade, do Centro de Estudos Brasileiros - México, D.F., pelos apoios concedidos;

Aos meus amigos de Piracicaba, especialmente ao Sr. Roberto Polloni e família: Vilma, Fabrício e Leonardo, pela confiança, amizade e apoio em todo momento;

Aos funcionários e colegas da ESALQ, especialmente os do Setor de Entomologia e Biblioteca, pelo apoio, amizade e convívio;

A todas as pessoas que de uma ou outra forma contribuíram na realização deste trabalho. 


\section{SUMÁRIO}

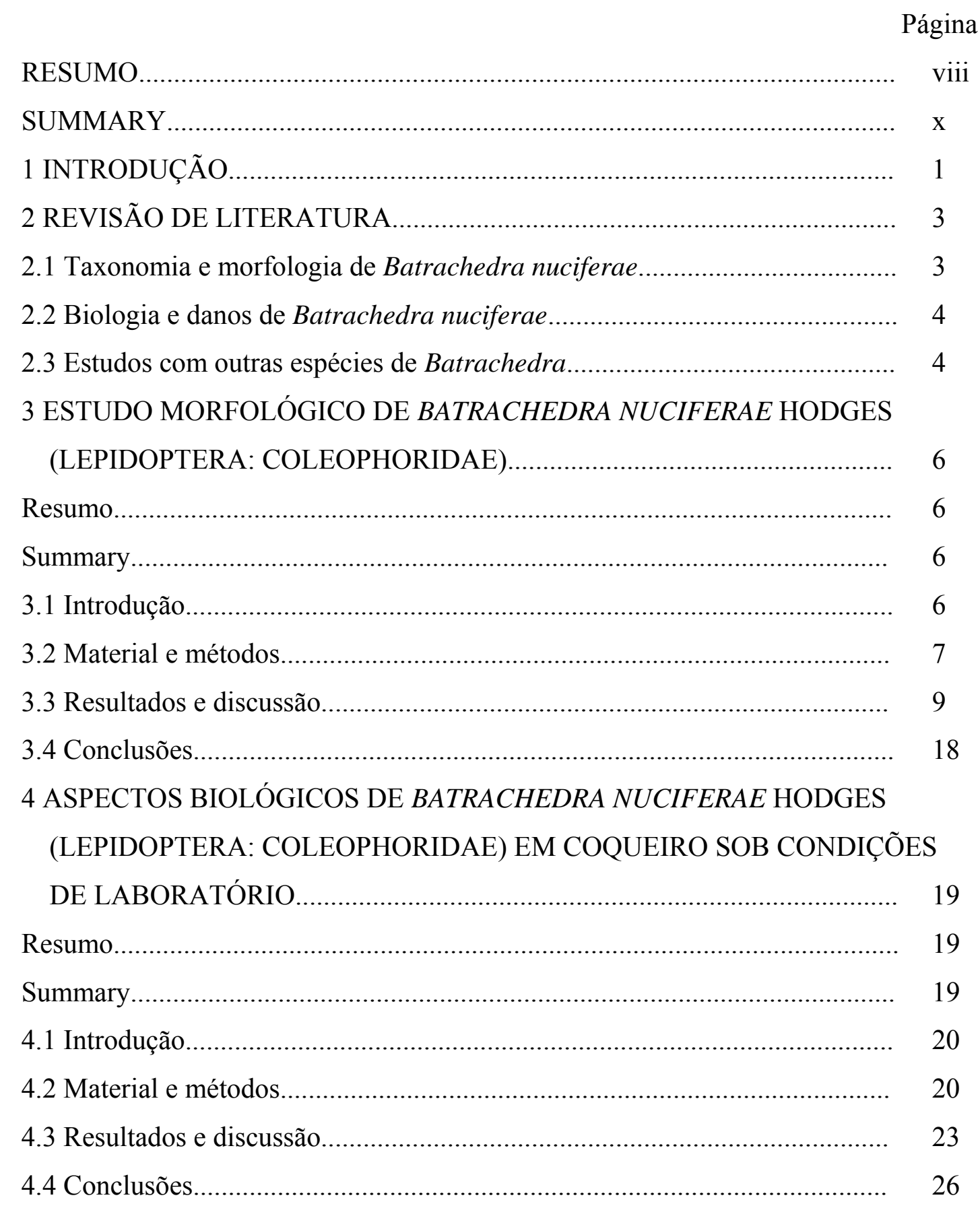


5 ATRAÇÃO DE BATRACHEDRA NUCIFERAE HODGES (LEPIDOPTERA: COLEOPHORIDAE) COM DIFERENTES COMPRIMENTOS DE ONDAS ELETROMAGNÉTICAS.............................................................................. 27

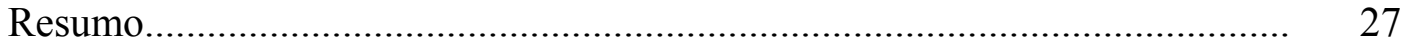

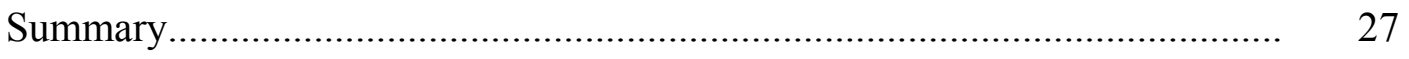

5.1 Introdução.................................................................................... 28

5.2 Material e métodos................................................................................ 29

5.3 Resultados e discussão........................................................................... 31

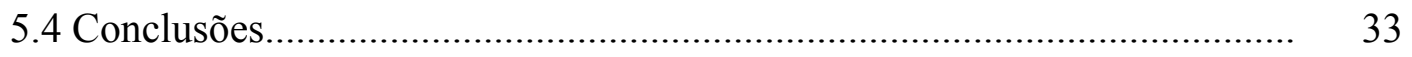

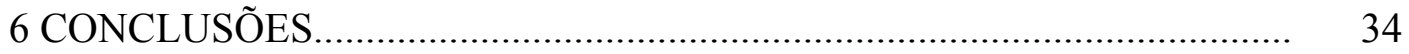

REFERÊNCIAS BIBLIOGRÁFICAS........................................................ 35 


\title{
MORFOLOGIA, BIOLOGIA E FOTOTROPISMO DE BATRACHEDRA NUCIFERAE HODGES (LEPIDOPTERA: COLEOPHORIDAE)
}

\author{
Autor: SAÚL SÁNCHEZ SOTO \\ Orientador: Prof. Dr. OCTAVIO NAKANO
}

\section{RESUMO}

Os objetivos do trabalho foram os de descrever a morfologia externa de Batrachedra nuciferae Hodges (ovo, larvas, pupas e adultos); determinar a duração e viabilidade das fases de ovo, larval, pré-pupal, pupal e adulta, número de ínstares, razão de crescimento, relação sexual, períodos de pré-oviposição e oviposição, e fecundidade da espécie criada em flores masculinas de coqueiro (Cocos nucifera L.), bem como avaliar o efeito de diferentes comprimentos de ondas eletromagnéticas sobre adultos visando o estabelecimento de um método de monitoramento desta praga. Os estudos foram conduzidos em laboratório. $\mathrm{O}$ ovo é ovalado com cório reticulado, semitranslúcido quando recém-colocado, tornando-se posteriormente amarelo-laranja. Largura: 0,4 $\pm 0,03 \mathrm{~mm}$, altura: $0,1 \pm 0,01 \mathrm{~mm}$. A larva neonata apresenta cabeça preta e prognata; tórax e abdome amarelo claro ou ligeiramente esbranquiçado, falsas pernas nos segmentos abdominais 3, 4, 5, 6 e 10. Comprimento: $1,1 \pm 0,12 \mathrm{~mm}$; largura da cápsula cefálica: $0,2 \pm 0,37 \mathrm{~mm}$. Larva de último ínstar com cabeça marrom-escuro, com seis estematas; primeiro segmento torácico com escudo dorsal preto e com a região lateral e ventral pigmentada de escuro; segundo e terceiro segmentos torácicos e segmentos abdominais esbranquiçados ou rosáceos nas regiões dorsal e lateral; pernas torácicas esbranquiçadas. Comprimento: $6,5 \pm 0,60 \mathrm{~mm}$; largura: 1,2 \pm 0,11 mm; largura da cápsula cefálica: $0,7 \pm 0,05 \mathrm{~mm}$. Pupa subcilíndrica; de coloração creme quando recém-formada, e marrom ligeiramente escura quando madura. A fenda genital está 
localizada no oitavo segmento na fêmea, e no nono segmento no macho. Comprimento da fềmea: $5,5 \pm 0,45 \mathrm{~mm}$, largura: $1,2 \pm 0,10 \mathrm{~mm}$. Comprimento do macho 4,9 $\pm 0,30$ $\mathrm{mm}$, largura: $1,1 \pm 0,08$. Adulto de coloração geral amarelo pálido ou palha, com escamas escuras nos palpos labiais, terço distal das antenas, nas asas anteriores e pernas. Entre o fim do primeiro terço e início do segundo terço das asas anteriores existe sempre uma mancha escura de forma mais ou menos oval ou alongada disposta longitudinalmente, e no terço distal com freqüência aparecem cerca de oito manchas escuras irregulares localizadas nas margens. O ápice do abdome é truncado com escamas brancas na fêmea e de forma oval com pêlos brancos no macho. Envergadura da Fêmea: 10,7 $\pm 1,06 \mathrm{~mm}$; do macho: $9,1 \pm 0,88 \mathrm{~mm}$. Sob condições de $25^{\circ} \mathrm{C}, 60 \%$ UR e $12 \mathrm{~h}$ fotofase, a duração das fases de ovo, lagarta, pré-pupa, pupa e adulto foi de $3,2 \pm 0,2$ dias, 9,2 $\pm 1,7$ dias, $2,3 \pm 0,8$ dias, 7,5 $\pm 0,6$ dias e 13,7 $\pm 2,5$ dias, respectivamente. A viabilidade das fases imaturas foi de $100 \%, 85,4 \%, 95,7 \%$ e $97,7 \%$, respectivamente. A fase larval apresentou três ínstares, sendo a média da razão de crescimento de 1,761 \pm 0,003. A relação sexual de adultos foi de 1: 1,2 ( $($ : đ) ), o período de pré-oviposição foi de 2,6 $\pm 1,1$ dias e o de oviposição de 11,3 $\pm 2,3$ dias, sendo a fecundidade de 31,5 \pm 18,3 ovos por fêmea. Das ondas eletromagnéticas avaliadas, emitidas pelas lâmpadas fluorescentes Black Light Blue (F15T8-BLB), Black Light (F15T8-BL), Plant Light (F15T8-PL), Blue (F15T8-B), Gold (F15T8-GO) e Luz do Dia, as que mais atraíram os adultos foram as ondas ultra violetas (BLB e $\mathrm{BL}$ ), entre as quais não houve diferença estatística significativa. 


\title{
MORPHOLOGY, BIOLOGY AND PHOTOTROPISM OF BATRACHEDRA NUCIFERAE HODGES (LEPIDOPTERA: COLEOPHORIDAE)
}

\author{
Author: SAÚL SÁNCHEZ SOTO \\ Advisor: Prof. Dr. OCTAVIO NAKANO
}

SUMMARY

The aim of this work was to describe the outer morphology of Batrachedra nuciferae Hodges (egg, larvae, pupae and adults), to determine the duration and viability of the egg, larval, prepupal, pupal and adult stages, number of instars, growth ratio, sex ratio, preoviposition and oviposition periods, and fecundity of the species reared in male coconut (Cocos nucifera L.) flowers, as well as to evaluate the effect of different lengths of electromagnetic waves on adults in order to set a monitoring method to this pest. The studies were conducted in laboratory. The egg is oval-shaped with reticulate semitranslucid chorion, when newly laid, later becoming yellowish-orange. Width: 0.,4 $\pm 0.03 \mathrm{~mm}$, height: $0 ., 1 \pm 0.01 \mathrm{~mm}$. The neonate larva has a black prognathous head, light yellow or slightly whitish thorax and abdomen, false legs in abdominal segments 3 , 4, 5, 6 and 10. Length: $1.1 \pm 0.12 \mathrm{~mm}$; width of the cephalic capsule: $0.2 \pm 0.37 \mathrm{~mm}$. The last instar larva is dark-brown headed, with six stemmata; first thorax segment with a black dorsal shield and dark-pigmented lateral and ventral regions; whitish second and third thorax segments and abdominal segments or pinkish dorsal and lateral regions; whitish thorax legs. Length: $6.5 \pm 0.60 \mathrm{~mm}$; width: $1.2 \pm 0,11 \mathrm{~mm}$; Length of the cephalic capsule: $0.7 \pm 0.05 \mathrm{~mm}$. Subcylindrical pupa, beige-colored when newly formed and slightly dark brown when mature. The genital slash is located in the eighth segment in females and ninth in males. Female length: $5.5 \pm 0.45 \mathrm{~mm}$, width: $1.2 \pm 0.10$ mm. Male length: $4.9 \pm 0.30 \mathrm{~mm}$, width: $1.1 \pm 0.08$. Overall adult color is pale yellow or 
sand, with dark scaled in labial palpi, distal third of antennae, in fore wings and legs. Between the first third end and beginning of second third of anterior wings there is always a dark spot somewhat oval-shaped or elongated longitudinally, and on the distal third about eight irregular dark spots in the margins are often found. The top abdomen is truncated with white scales in females and is oval-shaped with white hairs in males. Female span: $10.7 \pm 1,06 \mathrm{~mm}$; male span: $9.1 \pm 0.88 \mathrm{~mm}$. Under $25^{\circ} \mathrm{C}, 60 \% \mathrm{RH}$ and $12-$ hour photophase conditions, the duration of the egg, larva, prepupa, pupa and adult stages was $3.2 \pm 0.2$ days, $9.2 \pm 1.7$ days, $2.3 \pm 0.8$ days, $7.5 \pm 0.6$ days and $13.7 \pm 2.5$ days, respectively. The viability of the immature stages was $100 \%, 85.4 \%, 95.7 \%$ and $97.7 \%$, respectively. The larval stage presented three instars, with mean growth ratio of $1.761 \pm 0.003$. The adult sex ratio was $1: 1.2\left(q: \oint^{\Uparrow}\right)$, the period of preoviposition $2.6 \pm$ 1.1 days and oviposition $11.3 \pm 2.3$ days, with fecundity of $31.5 \pm 18.3$ eggs per female. Regarding the evaluated electromagnetic waves emitted by fluorescent lamps Black Light Blue (F15T8-BLB), Black Light (F15T8-BL), Plant Light (F15T8-PL), Blue (F15T8-B), Gold (F15T8-GO) and Daylight, the more attractant to adults were the ultraviolet waves (BLB and BL), among which no significant statistical difference was found. 


\section{INTRODUÇÃO}

O coqueiro (Cocos nucifera L.) é uma frutífera importante no Brasil, onde existem aproximadamente 300 mil hectares plantadas (Cuenca, 1998; Tonet \& Pelinson, 1999).

As pragas constituem um dos principais problemas que limitam seriamente a produção de coco no Brasil (Ferreira et al., 1998a; Moura, 1999). De acordo com Bondar (1940a), são conhecidas cerca de 80 espécies de insetos que danificam o coqueiro neste país. A importância delas pode variar de uma região a outra, dependendo das condições climáticas, da composição da flora associada e das técnicas de manejo adotadas (Ferreira et al., 1998b).

Entre estas espécies está Batrachedra nuciferae Hodges (Lepidoptera: Coleophoridae), a qual foi estudada por Bondar (1940a, 1940b) como Batrachedra perobtusa Meyrick (Hodges, 1966). As larvas destroem o pólen, diminuindo assim a probabilidade de fecundação das flores femininas, e conseqüentemente a frutificação das palmeiras (Bondar, 1940a, 1940b). De acordo com Arnal et al. (1998) este inseto pode ser de grande importância especialmente em programas de melhoramento genético e produção comercial de híbridos nos quais se utilizam coqueiros anões, pois existe uma relação entre a altura da planta e a incidência da praga: na menor altura há maior incidência.

Embora a variedade gigante represente atualmente $70 \%$ da exploração do coqueiro no Brasil (Aragão et al., 1999), a importância de B. nuciferae pode aumentar porque a área cultivada com a variedade anã tem se expandido nos últimos anos nas diferentes regiões deste país devido à comercialização da água de coco, que começou recentemente a ser industrializada (Aragão et al., 1999; Pires et al., 1999). Além disso, a utilização da variedade anã tem aumentado na produção de coqueiros híbridos, devido às 
vantagens agronômicas e econômicas que estes oferecem, e nos programas de melhoramento genético que existem atualmente no país (Aragão et al., 1999).

A praga foi identificada recentemente danificando coqueiros anões no estado de São Paulo (Sánchez Soto \& Nakano, 2002), onde tem se optado pela cultura dessa variedade para a produção de água de coco, e onde atualmente um dos problemas que limitam a produção é a baixa porcentagem de formação de frutos devido ao ataque de insetos (Tonet \& Pelinson, 1999).

A informação que existe sobre $B$. nuciferae é escassa, havendo a necessidade de desenvolver pesquisas básicas e aplicadas visando estabelecer o seu controle. A espécie é citada somente por Bondar (1940a, 1940b), Hodges (1966), Arnal et al. (1998) e Sánchez-Soto \& Nakano (2002), que mencionam alguns aspectos da sua biologia, morfologia, distribuição geográfica ou medidas de combate.

Tendo em vista o alto potencial de $B$. nuciferae como inseto de importância econômica para a cultura do coqueiro no Brasil, foi realizado este trabalho com os seguintes objetivos: 1) Descrever a morfologia externa de B. nuciferae nas diferentes fases do seu ciclo biológico, 2) conhecer alguns aspectos sobre a biologia desse inseto desenvolvido em flores de coqueiro e 3) avaliar diferentes comprimentos de ondas eletromagnéticas na atração de adultos visando estabelecer um método para o monitoramento da praga. 


\section{REVISÃO DE LITERATURA}

\subsection{Taxonomia e morfologia de Batrachedra nuciferae}

Considerado dentro do grupo dos microlepidópteros da superfamília Gelechioidea (Bradley, 1989), o gênero Batrachedra Herrich-Schäffer, tem sido incluído progressivamente nas famílias Cosmopterigidae, Momphidae e Coleophoridae (Nye \& Fletcher, 1991); porém, trabalhos mais recentes relacionados com a descrição de novas espécies, citam este gênero na família Batrachedridae (Sinev, 1993; Nel, 1998).

Hodges (1966) fez a descrição original de Batrachedra nuciferae baseando-se nas características da genitália de machos e fêmeas, não fazendo a descrição externa do adulto devido à deterioração dos exemplares disponíveis. Embora Bondar (1940a, 1940b) trabalhou com B. nuciferae citando-a como Batrachedra perobtusa Meyrick (Hodges, 1966), a descrição do adulto apresentada por ele é uma tradução da diagnose original de B. perobtusa Meyrick (Meyrick, 1922). Segundo Hodges (1966), Bondar (1940b) estudou esta praga com o nome de B. perobtusa com base numa identificação realizada por Busk. Hodges (1966) separou B. perobtusa do gênero Batrachedra constituindo com ela o gênero Ifeda, definindo $I$. perobtusa com espécie única do gênero.

De acordo com a informação apresentada por Hodges (1966), B. nuciferae pode ser separada de outras espécies de Batrachedra que ocorrem no novo mundo, considerando principalmente as características da genitália feminina.

Em relação á fase larval, Bondar (1940a, 1940b) menciona o seguinte: “A lagarta é minúscula, comprimento 6-7 $\mathrm{mm}$, largura 1,2 $\mathrm{mm}$; a cor é branca, ás vezes ligeiramente rosada. Cabeça preta. Primeiro anel torácico escurecido no lado ventral, no dorso com uma placa preta. Patas e pseudopodios brancos”. 


\subsection{Biologia e danos de Batrachedra nuciferae}

As larvas de B. nuciferae abundam nas inflorescências de $C$. nucifera, escondendo-se e alimentando-se dentro das flores masculinas. Ao destruir o pólen diminuem a probabilidade da fecundação das flores femininas, reduzindo conseqüentemente a frutificação das palmeiras (Bondar 1940a, 1940b). Segundo este autor, os danos causados pela praga ocorrem durante a estação seca, na qual as larvas podem destruir a totalidade das flores masculinas, especialmente em cachos com a espata fendida cujas flores tardam em abrir pelo tempo seco o por estarem os abusos atacados pelo pulgão Cerataphis lataniae ou pela cochinilha Aspidiotus destructor. Na Venezuela, esta praga foi constatada danificando flores femininas de coqueiros, além de flores masculinas (Arnal et al., 1998).

De acordo com Arnal et al. (1998), as larvas fazem uma rede similar a uma teia de aranha, a qual é acompanhada de excrementos e partes das flores danificadas. A pupa se forma dentro de um pequeno casulo de seda tecido pela larva, o qual fica aderido a qualquer objeto, de preferência palhas secas das palmeiras, protegidas contra as chuvas, ou no meio das flores masculinas acumuladas nas axilas da copa das plantas (Bondar 1940a, 1940b). No que respeita ao ciclo biológico da espécie, esse autor somente menciona que o ciclo completo tem uma duração aproximada de 15 a 18 dias.

\subsection{Estudos com outras espécies de Batrachedra}

De acordo com Hodges (1966), existem pelo menos aproximadamente 140 espécies de Batrachedra distribuídas nas diferentes regiões do mundo. Não considerando a descrição original delas, feita basicamente com a fase adulta, os estudos sobre esse gênero têm sido feitos com espécies que danificam plantas de importância econômica, sendo as mais estudadas Batrachedra arenosella Walker, praga do coqueiro, e Batrachedra amydraula Meyrick, praga da palmeira Phoenix dactylifera L., ocorrendo a primeira na Indonésia, Austrália, Papua-Nova Guiné, Vanuatu, Fidji, Ilhas 
Salomão e Malásia, e a segunda no Iraque, Israel, Iêmen, Bahrain, Egito e Arábia Saudita (Lever, 1969; Vilardebo, 1973; Zhang, 1994).

Em relação a estudos sobre morfologia de fases imaturas e sobre aspectos biológicos, além das duas espécies já mencionadas, tem-se informação sobre Batrachedra pinicolella (Duponchel), praga de coníferas na Balkaria (Bolov \& Sinev, 1990), e sobre Batrachedra rixator Hodges, praga do "fique" (Furcraea spp.) na Colômbia (Vélez-Angel, 1981). Algumas características gerais das larvas desse gênero são mencionadas por Stehr \& Martinat (1987) e Stehr (1987a, 1987b). Este último apresenta um desenho da larva de Batrachedra linaria Clarke coletada em folhas de Agave sp. no México, e comenta que se precisam de mais estudos das formas imaturas do gênero Batrachedra.

Em quanto ao fototropismo, Kimber (2002) menciona a atratividade da luz para adultos de Batrachedra praeangusta (Haworth) . 


\section{ESTUDO MORFOLÓGICO DE BATRACHEDRA NUCIFERAE HODGES (LEPIDOPTERA: COLEOPHORIDAE)}

\section{Resumo}

Batrachedra nuciferae Hodges, 1966 (Lepidoptera: Coleophoridae) constitui uma praga da cultura do coqueiro (Cocos nucifera L.) no Brasil. As larvas destroem o pólen diminuindo a probabilidade de fecundação das flores femininas e conseqüentemente a produção do coqueiro. O presente trabalho é uma contribuição para a identificação dessa espécie. São apresentadas descrições dos caracteres morfológicos externos do ovo, da larva neonata e de último ínstar, da pupa ( $q$ e $\widehat{\delta}$ ) e do adulto ( $q$ e §), bem como ilustrações dessas quatro fases.

\section{Summary}

Batrachedra nuciferae Hodges, 1966 (Lepidoptera: Coleophoridae) is a pest of the coconut palm (Cocos nucifera L.) in Brazil. The larvae destroy pollen reducing the probability of female flowers fecundation and consequently the coconut production. The present paper is a contribution to the identification of this species. Characters of the external morphology of egg, first and last larval instar, pupa ( $q$ and $\curvearrowright$ ) and adult ( $q$ and §) are described and illustrated.

\subsection{Introdução}

A incidência de pragas constitui um dos problemas que limitam seriamente a produção da cultura do coqueiro (Cocos nucifera L.) no Brasil (Ferreira et al., 1998a), 
país que tem aproximadamente 300 mil hectares plantadas (Cuenca, 1998; Tonet \& Pelinson, 1999). Bondar (1940a) citou aproximadamente 80 espécies de insetos que danificam o coqueiro no Brasil. A importância delas pode variar de uma região a outra, dependendo das condições climáticas, da composição da flora associada e das técnicas de manejo adotadas (Ferreira et al., 1998b). Entre essas espécies está Batrachedra nuciferae Hodges, que foi estudada por Bondar (1940a, 1940b) como Batrachedra perobtusa Meyrick (Hodges, 1966). De acordo com Bondar (1940a, 1940b), as larvas se alimentam no interior das flores masculinas destruindo o pólen e diminuindo, conseqüentemente, a probabilidade de fecundação das flores femininas e a produção do coqueiro. A espécie também ocorre na Venezuela (Arnal et al., 1998) e no Brasil tem sido registrada para os estados da Bahia (Hodges, 1966) e São Paulo (Sánchez-Soto \& Nakano, 2002).

Hodges (1966) descreveu B. nuciferae baseando-se nas características da genitália de fêmeas e machos, e não fez a descrição externa do adulto devido à deterioração dos exemplares disponíveis. Embora Bondar (1940a, 1940b) tenha estudado essa praga, citando-a como B. perobtusa (Hodges, 1966), a descrição do adulto publicada por ele é uma tradução da diagnose original de $B$. perobtusa feita na língua inglesa por Meyrick (1922); porém, a descrição da larva (Bondar, 1940a, 1940b) corresponde positivamente a $B$. nuciferae.

As publicações de Hodges (1966) e de Bondar (1940a, 1940b) são as únicas que apresentam informação sobre a morfologia de B. nuciferae, havendo desconhecimento total das fases de ovo e pupa. No presente trabalho são apresentadas descrições e desenhos da espécie nas diferentes fases de seu ciclo biológico.

\subsection{Material e Métodos}

A coleta de material biológico foi realizada em plantas de coqueiro anão no Bairro Jacutinga, município de Araçatuba, SP. As flores com larvas foram colocadas em frascos de vidro de boca ampla com tampa telada $(17 \times 12 \mathrm{~cm})$. Para obter larvas desenvolvidas, bem como pupas e adultos, foram colocados acima das flores pedaços de 
guardanapo de coloração verde, que foram usados pelas larvas para puparem. O guardanapo verde serviu para melhor visualização dos casulos de $B$. nuciferae, que são de coloração esbranquiçada. Para garantir que as larvas eram da mesma espécie, estas foram observadas e comparadas com auxílio de uma lupa consultando Bondar (1940a, 1940b). Algumas delas foram fixadas em uma solução constituída por 9 partes de álcool etílico $80 \%$ e 1 parte de ácido acético glacial; 48 horas após foram colocadas em álcool $80 \%$ contendo uma pequena quantidade de glicerina (Holloway \& Bradley, 1987). Outras foram colocadas junto com os pedaços de guardanapo em placas de petri até atingir a fase de pupa. Destas, algumas foram fixadas do mesmo jeito que as larvas, e outras foram deixadas para obter adultos. Poucas horas após a emergência, adultos de ambos os sexos foram colocados dentro de pequenos frascos de vidro hermeticamente fechados e mortos deixando-os por cinco horas no congelador; a seguir foram montados em microalfinetes. Para a obtenção de ovos, um grupo de aproximadamente 30 adultos foi colocado em uma gaiola constituída por um tubo de PVC $(10 \times 10 \mathrm{~cm})$ fechado por duas placas de petri $(15 \mathrm{~cm})$, sendo que a placa basal continha um disco de papel filtro e, sobre este, um frasco de plástico $(3,5 \times 2,8 \mathrm{~cm})$ contendo mel 10\% como alimento, que era oferecido aos adultos mediante um rolo dental inserido num orifício da tampa do frasco. O tubo de PVC foi revestido internamente com uma folha de papel azul como substrato de oviposição. Foi utilizado papel azul para facilitar a observação dos ovos. A confirmação da espécie foi feita mediante estúdio das genitálias consultando Hodges (1966).

As observações foram feitas com microscópio estereoscópico; no caso de ovos e larvas utilizou-se também microscópio para observação de preparações em lâminas. As medições foram feitas com auxilio de uma ocular micrométrica adaptada ao microscópio estereoscópico considerando-se: largura e altura de ovos; comprimento do corpo e largura da cápsula cefálica das larvas recém eclodidas; comprimento e largura do corpo (no terceiro segmento abdominal) das larvas de último ínstar, bem como a largura da sua cápsula cefálica; comprimento e largura (entre metatórax e primeiro segmento abdominal) das pupas, e envergadura dos adultos representada pela soma do comprimento das asas anteriores e a largura do tórax em nível de inserção das asas. 
Para o estudo da quetotaxia da cabeça, tórax e abdome foram utilizadas 20 larvas de último ínstar. Após separar a cabeça do corpo, ambos foram clarificados com $\mathrm{KOH}$ $10 \%$; posteriormente, o corpo foi colocado sobre uma camada de parafina dentro de uma placa de petri sendo feito um corte longitudinal dividindo-o em duas partes iguais, das quais a que corresponde ao lado esquerdo do inseto foi estirada numa lâmina de vidro para o estudo e elaboração do mapa de cerdas. Foi realizado também o mapa de cerdas da cabeça, e desenho da mandíbula direita e espinarete. Os desenhos foram feitos usando câmara clara adaptada ao microscópio estereoscópico. Utilizou-se o sistema de nomenclatura de cerdas proposto por Hinton (1946) para as cerdas do tórax e abdome, e a nomenclatura do mesmo autor modificada por Stehr (1987c) para as cerdas e poros da cabeça. Para o reconhecimento de apêndices e outras estruturas das pupas consultou-se o trabalho de Mosher (1969).

\subsection{Resultados e Discussão}

Ovo. Ovalado e moderadamente convexo dorsalmente; cório reticulado com minúsculos círculos na sua superfície; semitranslúcido quando recém-colocado, posteriormente se torna amarelo- claro, e depois amarelo-laranja (Figura 1). Largura: 0,4 $\pm 0,03 \mathrm{~mm}$, altura: $0,1 \pm 0,01 \mathrm{~mm}(\mathrm{n}=15)$.
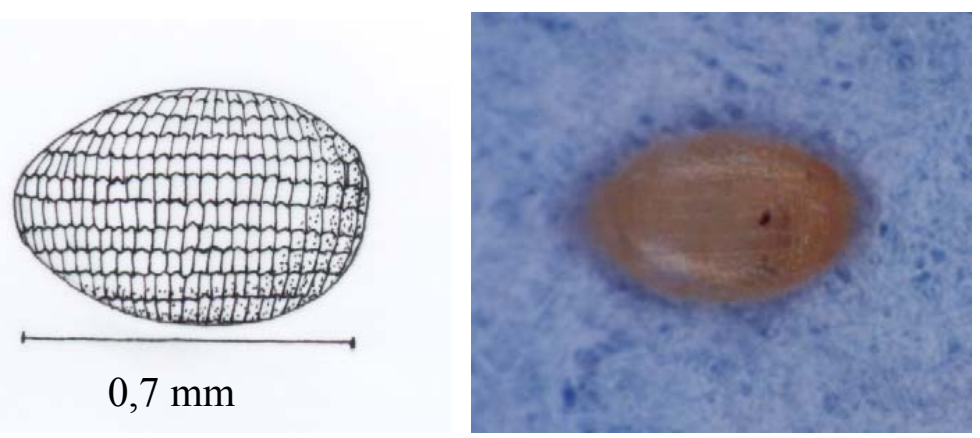

Figura 1 - Aspecto dorsal do ovo de B. nuciferae 
Larva neonata. Cabeça preta e prognata; tórax e abdômen amarelo claro ou ligeiramente esbranquiçado, exceto uma pequena faixa de cor preta presente na base das pernas torácicas; presença de falsas pernas nos segmentos abdominais 3, 4, 5, 6 e 10 . Cabeça e protórax mais largos do que o resto do corpo. Comprimento: $1,1 \pm 0,12 \mathrm{~mm}$; largura da cápsula cefálica: $0,2 \pm 0,37 \mathrm{~mm}(\mathrm{n}=10)$.

Larva de último ínstar. Cabeça marrom-escuro (Figura 2), com seis estematas; mandíbula e espinarete como na Figura 3C e 3D, respectivamente. Primeiro segmento

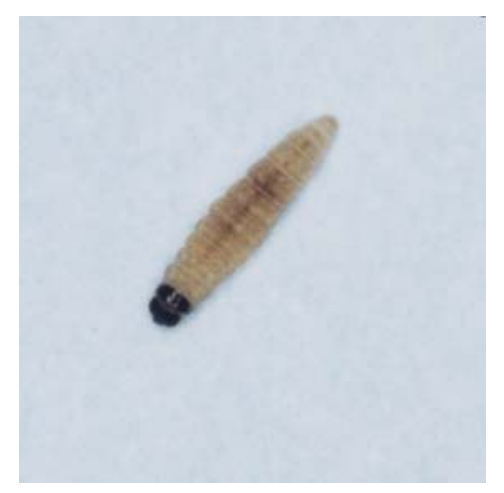

Figura 2 - Aspecto dorsal da larva de último ínstar de B. nuciferae

torácico com escudo dorsal preto e com a região lateral e ventral pigmentada de escuro; segundo e terceiro segmentos torácicos e segmentos abdominais esbranquiçados ou rosáceos nas regiões dorsal e lateral; pernas torácicas brancas com a base das coxas e lateral dos fêmures, tíbias e tarsos das pernas anteriores freqüentemente escurecidos; ganchos das falsas pernas com arranjo biordinal em círculo nos segmentos abdominais 3-6 e biordinal-transversal no segmento 10. Comprimento: $6,5 \pm 0,60 \mathrm{~mm}$; largura: $1,2 \pm$ 0,11 mm; largura da cápsula cefálica: $0,7 \pm 0,05 \mathrm{~mm}(\mathrm{n}=20)$.

Quetotaxia. Cabeça: As cerdas mais longas são P1, A1, A3 e S2; poro AFa perto da cerda $\mathrm{AF} 1$; poro $\mathrm{Pb}$ em posição ântero-dorsal à cerda $\mathrm{P} 2$ (Figura 3A e 3B). Tórax: As cerdas mais longas nos três segmentos são D2, SD1, L1 e SV1; protórax com as cerdas do grupo L em posição ântero-ventral ao espiráculo, cerda SV2 com aproximadamente a 
metade do comprimento de SV1, e com MXD1 sobre o escudo. Abdome: As cerdas mais longas são D2, SD1, L1 e L3 nos segmentos 1-7; D2, SD1, L1 e SV1 nos segmento 8 e 9, e SD1 e SD2 no segmento 10; nos segmentos 3-6 SV1 é menor do que nos outros segmentos e SV2 é ligeiramente maior e ântero-ventral com relação a SV1; nos segmentos 1-8 SD2 se localiza muito próxima a SD1, em posição ântero-dorsal a ela; no segmento $9 \mathrm{SD} 1$ freqüentemente é mais fina do que as outras cerdas; o grupo SV é constituído por uma cerda nos segmentos 8 e 9, por duas cerdas nos segmentos 1 e 7 , e por três cerdas nos segmentos 2-6 (Figura 4).

Pupa. Subcilíndrica; de coloração creme quando recém-formada, e marrom ligeiramente escura quando madura. Cabeça: vértice quase plano; fronte apresentando um par de cerdas com ápice curvado localizadas acima da base das antenas; olhos com duas cerdas na margem inferior; labro e mandíbulas bastante evidentes; palpos labiais prolongando-se aproximadamente até a metade dos palpos maxilares; antenas visíveis dorsalmente até a altura do mesonoto, ventralmente se aproximam à altura do ápice dos palpos maxilares, divergem um pouco distalmente e terminam comumente sobre o sexto segmento abdominal. Tórax: os três segmentos são visíveis dorsalmente, sendo o pronoto menor e bastante estreito na sua região média onde se localizam duas cerdas; asas anteriores comumente terminando sobre o quinto segmento abdominal; asas posteriores visíveis até a margem anterior do segundo segmento abdominal em vista dorso-lateral; segmentos das pernas visíveis: fêmures, tíbias e tarsos protorácicos; tíbias e tarsos mesotorácicos, e tarsos metatorácicos, estes terminam comumente sobre o sexto segmento abdominal entre o ápice das antenas. Os apêndices estão soldados ao abdome até o quarto segmento abdominal, ficando livre o ápice das asas anteriores, das antenas e das pernas posteriores. Abdome: Com uma forte constrição entre os segmentos IV e V, V e VI, e VI e VII; sétimo segmento com duas saliências laterais em forma de pináculo portando no ápice uma cerda longa com a ponta curvada; oitavo segmento com duas 

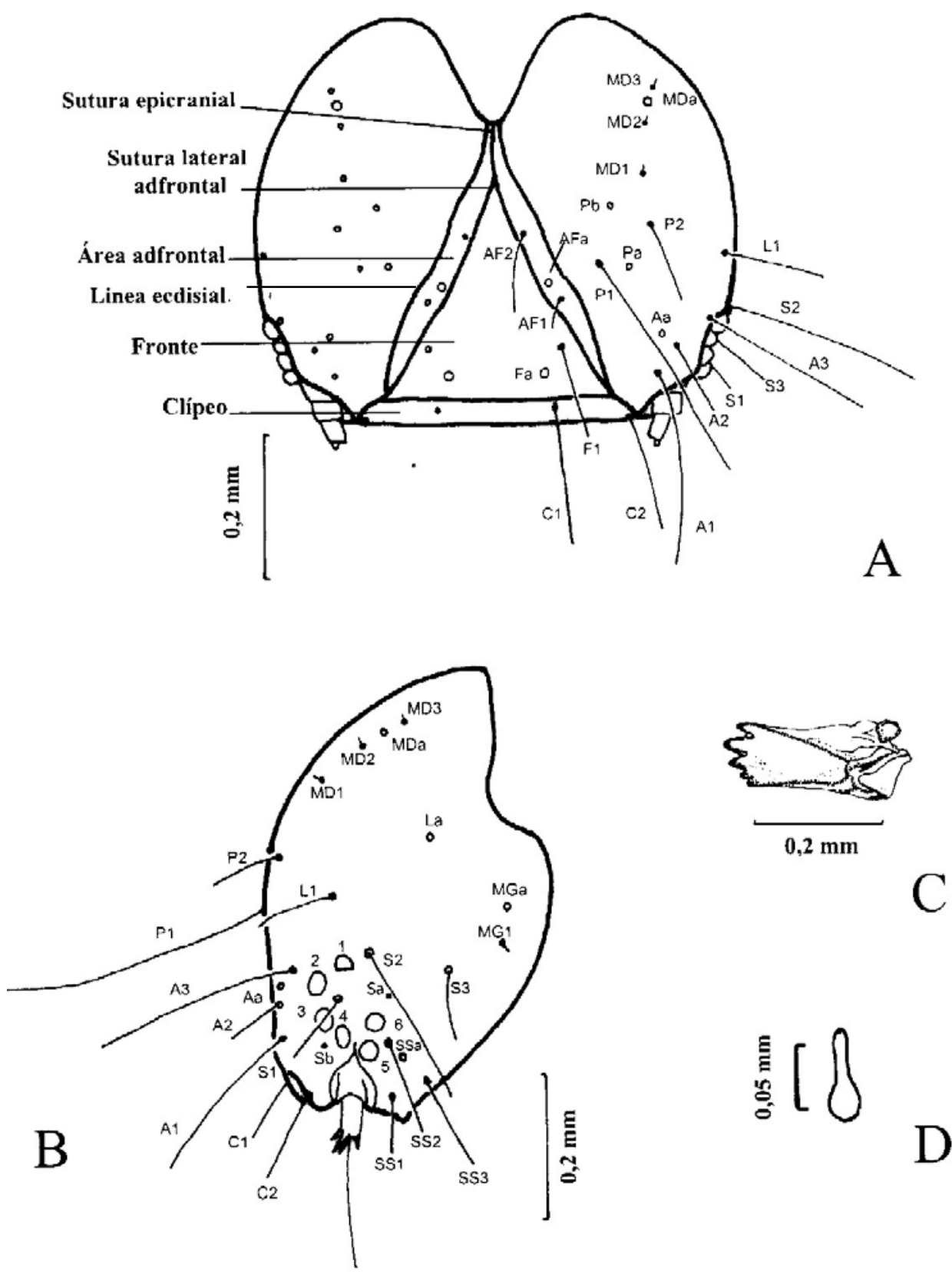

Figura 3 - Cabeça da larva de último ínstar de B. nuciferae: mapa de cerdas em vista frontal (A) e lateral esquerda (B), vista lateral interna da mandíbula direita (C) e vista ventral do espinarete (D) 


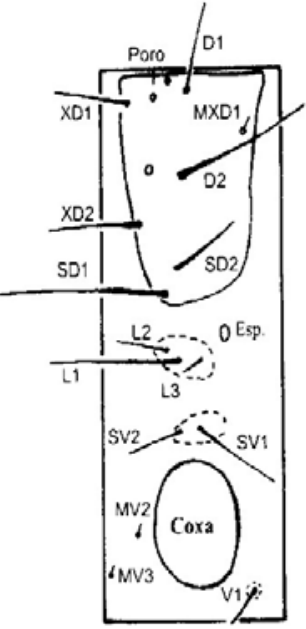

$\mathrm{T} 1$

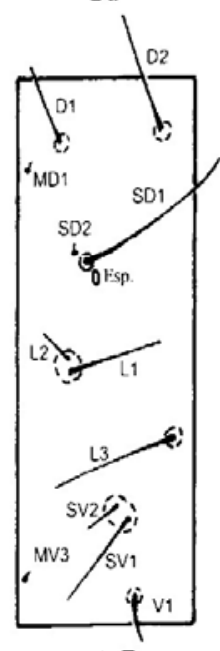

A 7

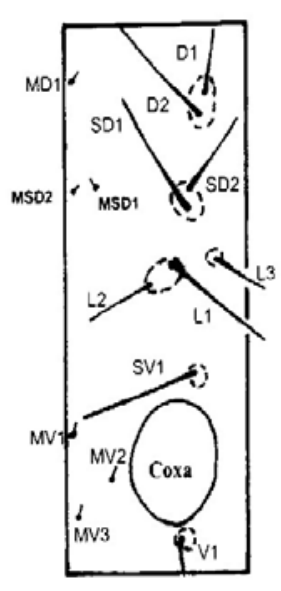

T $2-$ T 3

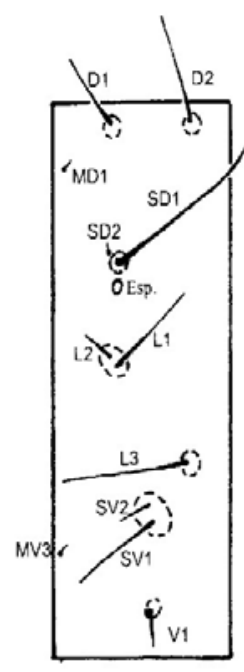

A 1

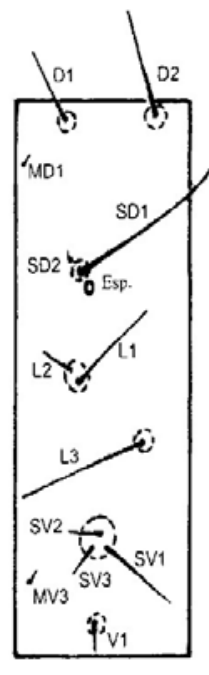

A 2
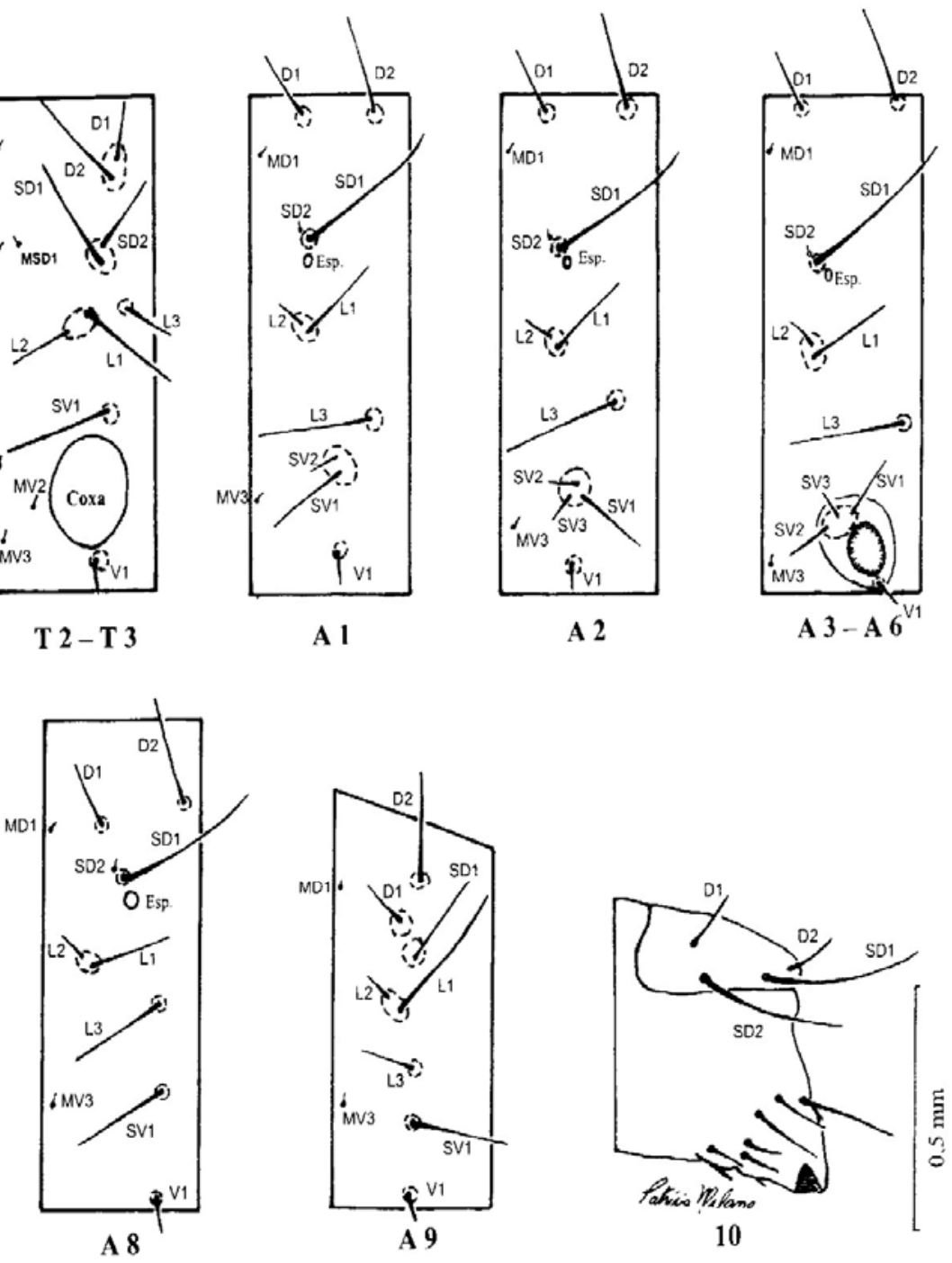

Figura 4 - Mapa de cerdas do tórax (T) e abdome (A) da larva de último ínstar de B. nuciferae 
saliências menores de contorno arredondado localizadas látero-ventralmente; décimo segmento com duas protuberâncias dorsais em forma de grossos ganchos triangulares, e com um tubérculo ventral com um grupo de cerdas com a ponta curvada (Figura 5A-C). Fenda genital localizada no oitavo segmento na fêmea, e no nono segmento no macho (Figura 5D). Fêmea: Comprimento: 5,5 \pm 0,45 mm, largura: 1,2 $\pm 0,10 \mathrm{~mm}(\mathrm{n}=10)$. Macho: comprimento: 4,9 $\pm 0,30 \mathrm{~mm}$, largura: $1,1 \pm 0,08(\mathrm{n}=9)$.

Adulto. Cabeça: espirotromba e palpos maxilares brancos. Palpos labiais com o primeiro segmento branco; segundo segmento branco com escamas pretas nos lados externo e interno distribuídas irregularmente desde a base até pouco mais da metade, às vezes quase unindo-se com um anel preto localizado no ápice; metade proximal do terceiro segmento branca com um anel preto no meio, e metade distal preta, às vezes com a ponta branca (Figura 6B); freqüentemente a coloração preta é mais clara na superfície interna dos três segmentos dos palpos labiais, e no terceiro segmento essa superfície pode ser toda escurecida. Antenas com as primeiras três quartas partes de coloração amarelo pálido e com anéis marrom ou pretos; o quarto distal freqüentemente com três anéis pretos e amplos, separados por outros anéis brancos divididos mais ou menos no meio por um pequeno anel preto; o segmento apical é branco (Figura 6C). Fronte branca ou creme, às vezes com algumas escamas cinza-claros; vértice freqüentemente com uma mistura de cores (cinza, marrom- claro e creme). Tórax: dorsalmente com uma mistura de cores (cinza, marrom-claro e creme), incluindo a tégula; lateral e ventralmente amarelo-pálido. Asas anteriores: superfície dorsal predominantemente amarelo-pálidos com manchas marrom-cinzas distribuídas irregularmente; este aspecto se deve à presença de escamas amarelo-pálidos e escamas com a parte basal clara e a apical marrom-cinza; estas freqüentemente se encontram mais agrupadas na margem posterior da asa dando-lhe um aspecto mais escuro nesta região (Figura 7A e 7B). Aproximadamente entre o fim do primeiro terço e início do segundo terço da asa existe sempre uma mancha escura de forma mais ou menos oval ou alongada disposta longitudinalmente; no terço distal com freqüência aparecem cerca de 

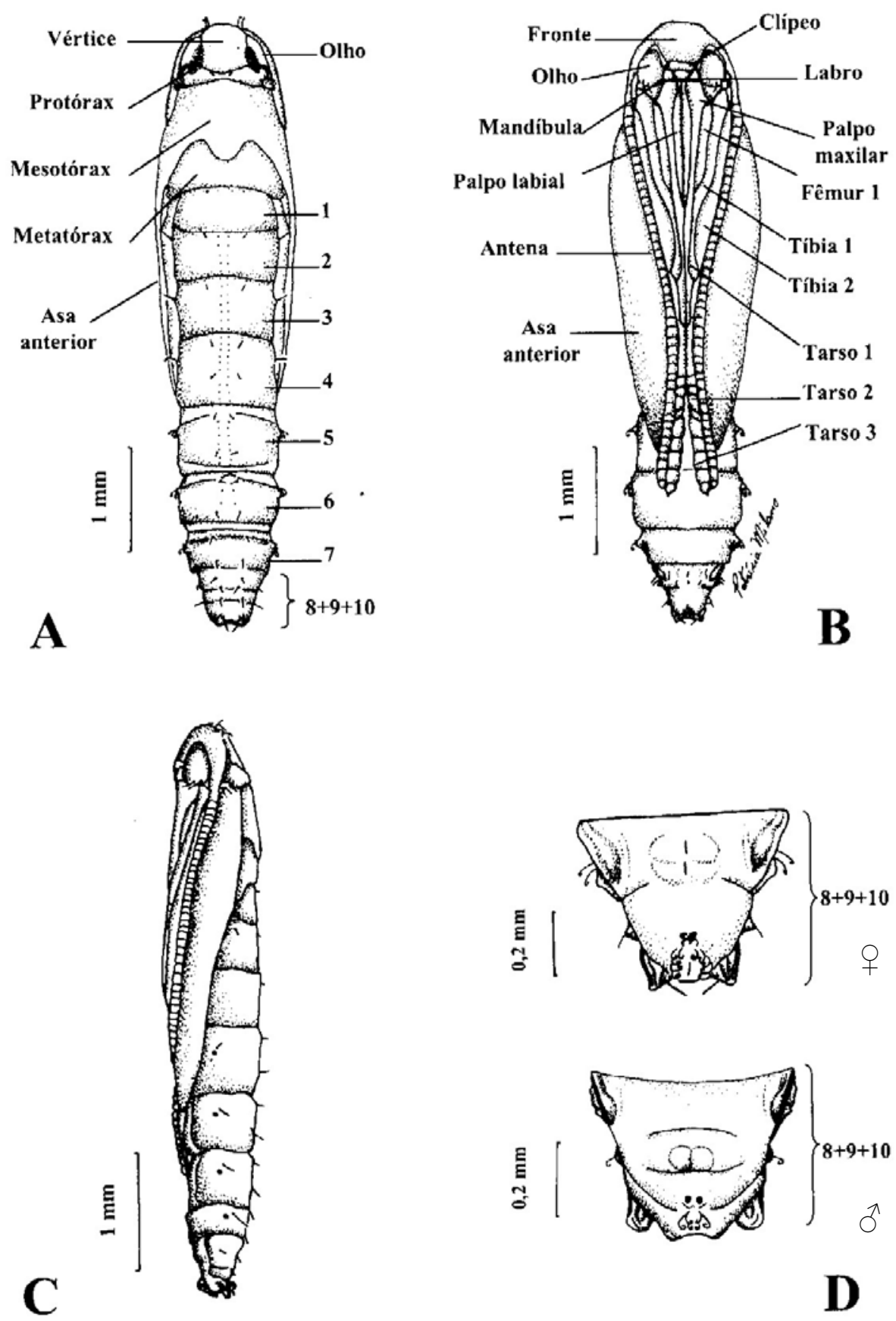

Figura 5 - Pupa de B. nuciferae: Aspecto dorsal (A), ventral (B), lateral esquerdo (C) e ápice abdominal da fêmea e do macho (D) 


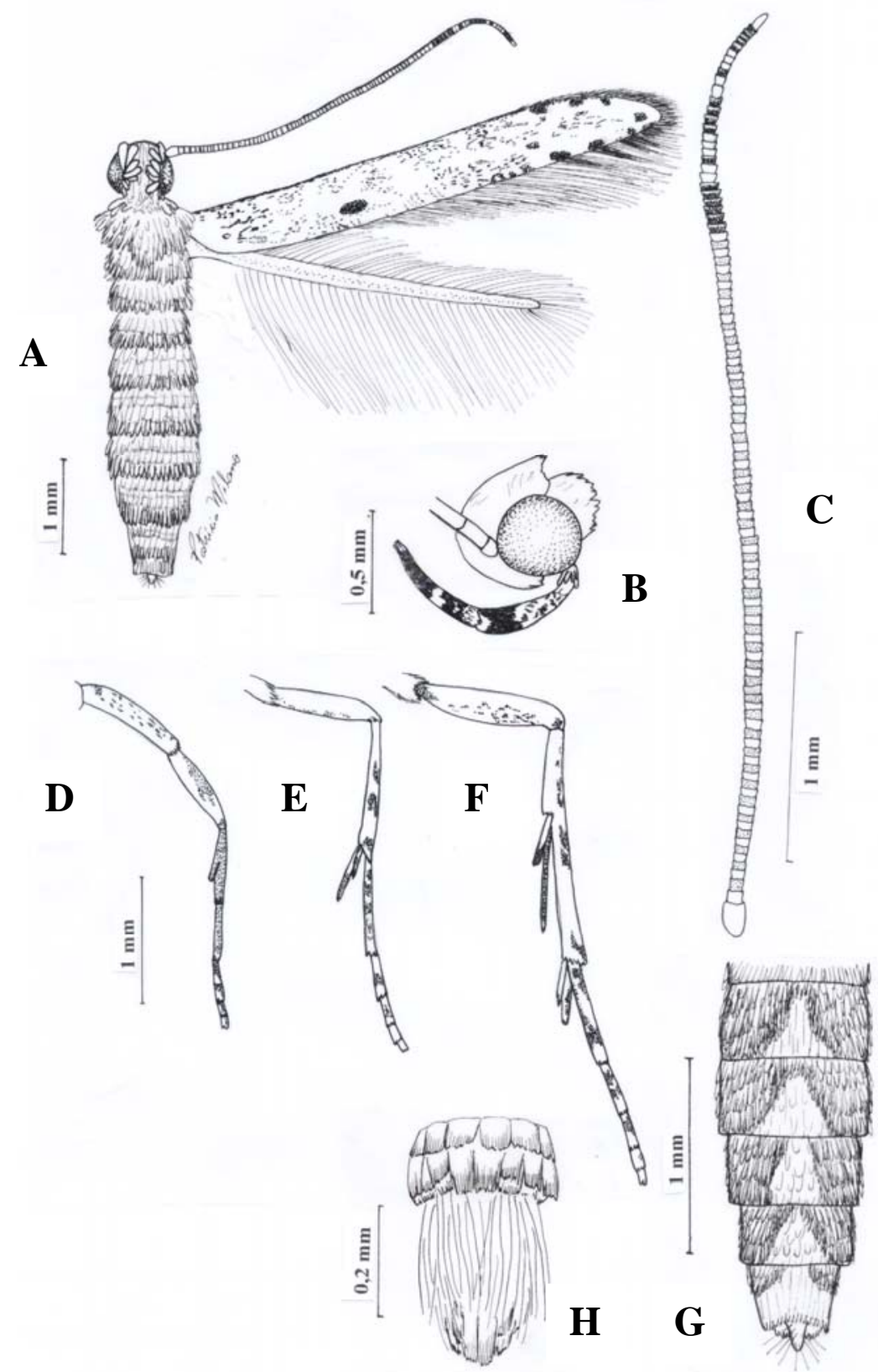

Figura 6 - Adulto de B. nuciferae: Aspecto dorsal (A), aspecto externo do palpo labial (B), antena (C), aspecto das pernas protorácicas (D), mesotorácicas (E) e metatorácicas (F) em vista ventral, aspecto ventral do abdome com o ápice abdominal correspondente à fêmea $(\mathrm{G})$ e ápice abdominal do macho $(\mathrm{H})$ 


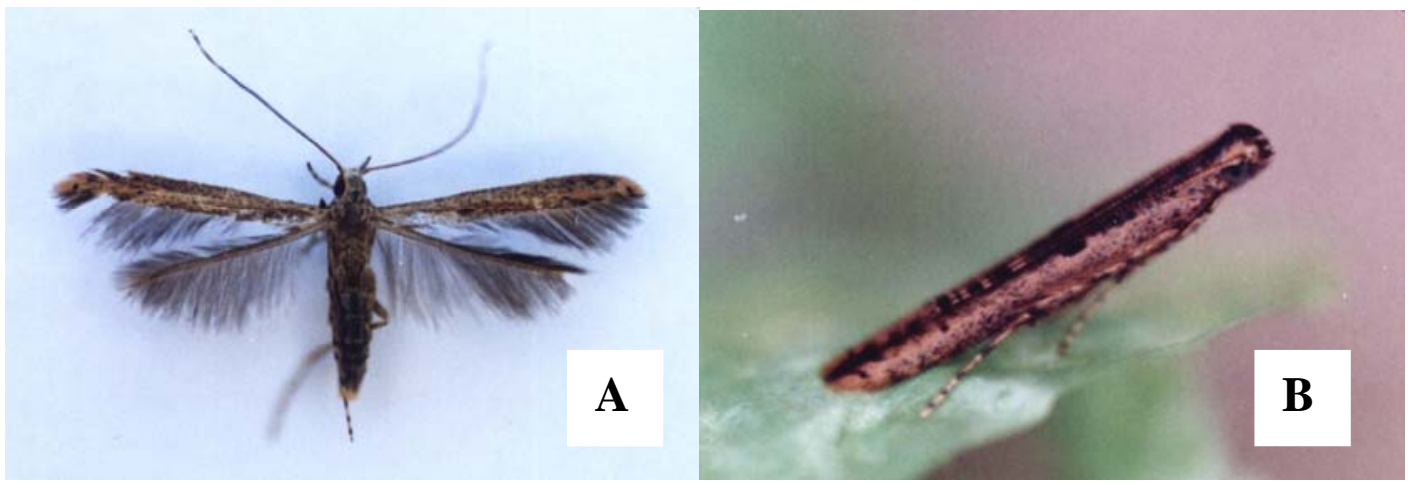

Figura 7 - Aspecto dorsal (A) e lateral (B) do adulto de B. nuciferae

oito manchas escuras irregulares localizadas nas margens (Figura 6A e 7A); superfície ventral das asas e cílios marrom-acinzentados. Asas posteriores com ambas superfícies e cílios marrom-acinzentados. Pernas branco-amarelas com manchas escuras (Figura 6DF). Abdome: dorsalmente com escamas marrom-cinza e creme; lateral e ventralmente com escamas branco-creme e escamas marrons, ficando uma área branca ventral de forma mais ou menos triangular nos últimos cinco ou quatro segmentos (Figura 6G). O ápice do abdome é truncado com escamas brancas na fêmea (Figura 6G) e de forma oval com pêlos brancos no macho (Figura 6H). Envergadura. Fêmea: 10,7 \pm 1,06 mm (n= 12); macho: $9,1 \pm 0,88 \mathrm{~mm}(\mathrm{n}=8)$.

A morfologia de B. nuciferae apresenta semelhanças com a de outras espécies do gênero nas quatro fases do ciclo de vida (Lever, 1969; Michael \& Habib, 1971; Bolov \& Sinev, 1990). A quetotaxia da larva de Batrachedra linaria Clarke ilustrada por Sterh (1987a) é muito semelhante à de B. nuciferae no relacionado às cerdas primárias, pois nesse desenho não foram incluídas as cerdas microscópicas propioceptores. A ilustração e descrição destas cerdas e poros no presente trabalho constituem uma contribuição para o conhecimento da morfologia da fase larval do gênero Batrachedra.

As descrições e desenhos aqui apresentados seriam úteis em trabalhos futuros para separar de forma prática os adultos de B. nuciferae de outros microlepidópteros associados com a cultura do coqueiro no Brasil (Lever, 1969); porém, a identificação da 
espécie deve ser sempre confirmada mediante o estudo das genitálias consultando o trabalho de Hodges (1966).

\subsection{Conclusões}

O presente trabalho oferece detalhes sobre a morfologia externa de B. nuciferae, que pode ser de grande ajuda na identificação da espécie nas fases de ovo, larva, pupa e adulta.

O mapa de cerdas da larva de último ínstar de B. nuciferae é o mais completo dentro do gênero Batrachedra . 


\section{ASPECTOS BIOLÓGICOS DE BATRACHEDRA NUCIFERAE HODGES (LEPIDOPTERA: COLEOPHORIDAE) EM COQUEIRO SOB CONDIÇÕES DE LABORATÓRIO}

\section{Resumo}

Foram estudados alguns aspectos da biologia de Batrachedra nuciferae Hodges (Lepidoptera: Coleophoridae) em flores masculinas de coqueiro (Cocos nucifera L.) sob condições controladas $\left(25^{\circ} \mathrm{C}, 60 \%\right.$ UR e $12 \mathrm{~h}$ fotofase). A duração das fases de ovo, larva, pré-pupa, pupa e adulta foi de 3,2 \pm 0,2 dias, 9,2 \pm 1,7 dias, 2,3 \pm 0,8 dias, 7,5 \pm 0,6 dias e 13,7 $\pm 2,5$ dias, respectivamente. A viabilidade das fases imaturas foi de $100 \%, 85,4 \%, 95,7 \%$ e $97,7 \%$, respectivamente. A fase larval apresentou três ínstares, sendo a média da razão de crescimento de $1,761 \pm 0,003$. A relação sexual de adultos foi de 1: 1,2 (ㅇ: đ̂), o período de pré-oviposição foi de 2,6 \pm 1,1 dias e o de oviposição de $11,3 \pm 2,3$ dias, sendo a fecundidade de 31,5 \pm 18,3 ovos por fêmea.

\section{Summary}

Some biological aspects of Batrachedra nuciferae Hodges (Lepidoptera: Coleophoridae) on male flowers of coconut (Cocos nucifera L.) under controlled conditions $\left(25^{\circ} \mathrm{C}, 60 \% \mathrm{RH}\right.$ and 12 - hour photophase) were studied. The mean period of egg, larval, pre-pupal, pupal and adult stages was $3.2 \pm 0.2$ days, $9.2 \pm 1.7$ days, $2.3 \pm$ 0.8 days, $7.5 \pm 0.6$ days and $13.7 \pm 2.5$ days, respectively. The viability of the immature stages was $100 \%, 85.4 \%, 95.7 \%$ and $97.7 \%$, respectively. The larval stage has three instars; the grown ratio was $1.761 \pm 0.003$. The sex ratio of adults was $1: 1.2\left(\odot\right.$ : $\left.{ }^{\Uparrow}\right)$, the 
pre-oviposition and oviposition period was $2.6 \pm 1.1$ days and $11.3 \pm 2.3$, respectively. The fecundity was $31.5 \pm 18.3$ eggs per female.

\subsection{Introdução}

Batrachedra nuciferae Hodges constitui uma praga da cultura do coqueiro (Cocos nucifera L.) no Brasil, sendo registrada sua ocorrência nos estados da Bahia (Bondar, 1940a, 1940b; Hodges, 1966) e São Paulo (Sánchez-Soto \& Nakano, 2002). As larvas destroem o interior das flores masculinas; ao alimentarem-se do pólen diminuem a probabilidade de fecundação das flores femininas e conseqüentemente a frutificação das palmeiras (Bondar, 1940a, 1940b). Os cachos atacados são reconhecidos porque nas flores danificadas surgem excrementos e redes similares a uma teia de aranha (Arnal et a1., 1998). Os danos são maiores na época da seca na qual as larvas podem destruir a totalidade das flores masculinas (Bondar, 1940a, 1940b).

Existe pouca informação sobre a biologia e comportamento de B. nuciferae. Bondar (1940a, 1940b), que estudou essa espécie com o nome de B. perobtusa Meyrick (Hodges, 1966), menciona que quando a espata abre a fềmea deposita os ovos nas inflorescências, de modo que ao desabrocharem as flores estas já estão invadidas pelas larvas; a fase de pupa ocorre dentro de um pequeno casulo de seda aderido as palhas secas ou no meio de flores masculinas acumuladas nas axilas da copa das palmeiras, e seu ciclo evolutivo completo é de aproximadamente 15 a 18 dias.

No presente trabalho foram estudados os seguintes aspectos biológicos de $B$. nuciferae em flores de coqueiro sob condições de laboratório: duração e viabilidade das fases de ovo, larval, pré-pupal e pupal; número e duração de cada ínstar larval; períodos de pré-ovoposição e oviposição; fecundidade, razão sexual e longevidade de adultos.

\subsection{Material e Métodos}

O estudo foi realizado no Departamento de Entomologia, Fitopatologia e Zoologia Agrícola da Escola Superior de Agricultura “Luiz de Queiroz”, Universidade 
de São Paulo, sob condições de $25^{\circ} \mathrm{C}$ de temperatura, $60 \%$ de umidade relativa e 12 horas de fotofase.

Para iniciar a criação coletaram-se cachos de coqueiro anão infestados com larvas e pupas no município de Araçatuba, São Paulo. Os cachos infestados foram colocados numa caixa de plástico $(50 \times 35 \times 35 \mathrm{~cm})$ com tampa telada, sendo regularmente umedecidos pulverizando água para manter umidade. Ao emergirem, os adultos foram transferidos para uma gaiola com armação de madeira e paredes teladas (30 x $30 \times 50 \mathrm{~cm}$ ) onde ficaram confinados e alimentados com solução de água e mel $10 \%$ contida em frascos de plástico $(5 \times 4 \mathrm{~cm})$. A solução ficou disponível para os insetos através de um chumaço de algodão inserido num orifício da tampa dos frascos. Para obter ovos, foram pendurados no interior da gaiola saquinhos $(5 \times 5 \mathrm{~cm})$ feitos com guardanapo branco de folha dupla com pontos depressivos na superfície, contendo flores frescas de coqueiro ligeiramente maceradas para estimular a oviposição. Os ovos foram colocados pelas fêmeas na superfície dos saquinhos, geralmente um ovo em cada ponto depressivo.

O trabalho iniciou-se com 130 ovos recém colocados pelas fêmeas sobre os saquinhos de guardanapo. Os ovos foram isolados fazendo pequenos recortes do guardanapo, cada um com um ovo. Os ovos foram umedecidos com água destilada sendo colocados individualmente dentro de um tubo de ensaio de $7 \mathrm{~cm}$ de comprimento e $1 \mathrm{~cm}$ de diâmetro. Os tubos foram tampados com um chumaço de algodão que se manteve moderadamente umedecido, e foram colocados de forma invertida numa base de isopor $(30 \times 20 \mathrm{~cm})$. O período de incubação foi determinado revisando os ovos a cada 12 horas até a eclosão das larvas.

As larvas foram criadas dentro dos mesmos tubos de ensaio alimentando-as com flores masculinas de coqueiro anão até atingir a fase de pré-pupa. Utilizaram-se flores fechadas que eram lavadas previamente com água da torneira e depois abertas intencionalmente para as larvas poderem alimentar-se do interior. As flores eram renovadas quando as larvas precisavam de mais alimento ou quando se constatavam flores com indícios de ataque por fungos. A cada renovação de alimento eram colocadas de uma a três flores de coqueiro por tubo, dependendo do grau de desenvolvimento das 
larvas. Para a determinação do período larval foram utilizadas um total de 110 larvas, das quais 13 foram estudadas par determinar o número de ínstares e duração de cada ínstar. As 13 larvas foram alimentadas com pólen fresco que era espalhado no interior dos tubos de ensaio e renovado a cada dia. Isto foi realizado com a finalidade de observar as mudas da cápsula cefálica. Para determinar a razão de crescimento da espécie, as mudas foram medidas utilizando uma ocular micrométrica acoplada a um microscópio estereoscópico.

A duração da fase pré-pupal foi determinada mediante observações a cada 12 horas considerando 94 indivíduos que atingiram esta fase das 110 larvas mencionadas anteriormente. O inicio desta fase é caracterizado pela cessação da atividade de alimentação das larvas, seguida pela formação do casulo de seda que ficou aderido comumente à parede do tubo. O fim da fase é determinado pela formação da pupa na qual fica aderida a muda da cápsula cefálica da larva de último ínstar.

A duração da fase de pupa foi determinada mediante observações a cada 24 horas desde o inicio da formação das pupas até a emergência dos adultos. Neste caso foram estudadas 90 pupas que atingiram este estágio das 94 pré-pupas já mencionadas. Da mesma maneira que as fases anteriores, a fase pupal ocorreu dentro dos tubos de ensaio.

A sexagem de adultos foi feita observando as diferenças morfológicas no extremo do abdome. Para determinar os períodos de pré-oviposição e oviposição, bem como a fecundidade e longevidade, foram utilizados 20 casais. Estes foram confinados em grupos de cinco, emergidos no mesmo dia, em gaiolas constituídas por um tubo de PVC $(20 \times 10 \mathrm{~cm})$ fechado com duas placas de petri de $15 \mathrm{~cm}$ de diâmetro, uma funcionando como base e outra como tampa, sendo que a placa basal continha um disco de papel filtro e, sobre este, um frasco de plástico $(5 \times 4 \mathrm{~cm})$ contendo solução de água e mel $10 \%$ como alimento, que era oferecido aos adultos mediante um chumaço de algodão inserido num orifício da tampa do frasco. O tubo de PVC foi revestido internamente com guardanapo branco de folha dupla com pontos depressivos na superfície como substrato de oviposição. Para estimular a oviposição foram colocadas 10 flores masculinas de coqueiro ligeiramente maceradas dentro de um saquinho que foi 
formado ao separar as duas capas que formam a folha dupla de guardanapo, na parte superior da gaiola.

\subsection{Resultados e Discussão}

A duração das fases imaturas, períodos de pré-oviposição e oviposição, e longevidade de adultos são apresentados na Tabela 1. De acordo com o teste de Tukey, constatou-se que os machos tiveram uma duração média significativamente superior à das fêmeas na fase de pupa; já na fase adulta não houve diferença significativa (Tabela 1). O período desde ovo até a morte do adulto foi em geral de 35,9 dias. A duração do ciclo evolutivo (15 - 18 dias) mencionado por Bondar (1940a, 1940b) possivelmente abarca desde a incubação até a emergência de adultos. No presente trabalho o período desde ovo até emergência de adultos foi de 19,9 $\pm 2,5$ dias (14,5 - 25,5 dias), e desde ovo até o inicio da oviposição o período foi de 22,5 \pm 3,6 dias (16,5 - 29,5 dias). Michael \& Habib (1971) registraram os seguintes dados biológicos de B. amydraula Meyrick, praga da palmeira Phoenix dactylifera L. no Médio Oriente, criada sob condições de $25^{\circ} \mathrm{C}$ de temperatura e $72,5 \pm 2,5 \%$ de umidade relativa: ovo: $5 \pm 0,7$ dias, larva: $17,9 \pm 0,7$ dias, pupa: $16,1 \pm 1,4$ dias, e adulto: $5,4 \pm 0,7$ dias, sendo o período total de vida de 44,4 dias. Para B. arenosella Walker, praga do coqueiro no sudeste Asiático e Oceania, a duração das fases de ovo, larva e pupa registrada na Malásia foi de 2 - 3 dias, 5 - 8 dias e 6 - 8 dias, respectivamente, e em Fidji de 4 dias, 10 - 14 dias e 9 - 11 dias, respectivamente (Lever, 1969).

Nas condições do presente estudo, a viabilidade das fases de ovo, larval, prépupal e pupal foi de $100 \%, 85,4 \%, 95,7 \%$ e $97,7 \%$, respectivamente, sendo a viabilidade total de $80 \%$. Na fase larval a mortalidade ocorreu em indivíduos que apresentaram manchas pretas na cutícula causadas possivelmente por organismos patogênicos, sendo estes também a possível causa de morte nas fases de pré-pupa e pupa.

A espécie apresentou três ínstares larvais, sendo o terceiro ínstar o de maior duração (Tabela 1). Embora não seja um fato comum, a presença de três ínstares larvais é registrada para a ordem Lepidoptera (Parra, 2001). Michael \& Habib (1971) 
determinaram seis ínstares em larvas de B. amydraula alimentadas com frutos imaturos de $P$. dactylifera. De acordo com Parra \& Haddad (1989) o número de ínstares pode

Tabela 1. Duração das fases imaturas, períodos de préoviposição e oviposição, e longevidade de adultos de $B$. nuciferae $\left(25^{\circ} \mathrm{C}, 60 \% \mathrm{UR}, 12\right.$ $\mathrm{h}$ fotofase)

\begin{tabular}{|c|c|c|}
\hline Fase & Duração (dias) & Amplitude \\
\hline Ovo & $3,2 \pm 0,26$ & $2,5-3,5$ \\
\hline $1^{\circ}$ instar & $2,7 \pm 0,40$ & $2-3$ \\
\hline $2^{\circ}$ instar & $2,3 \pm 0,56$ & $2-3$ \\
\hline $3^{\circ}$ instar & $4,2 \pm 0,92$ & $3-6$ \\
\hline Larva (total) & $9,2 \pm 1,72$ & $6-13$ \\
\hline Pré-pupa & $2,3 \pm 0,84$ & $1-7$ \\
\hline Pupa $\varnothing$ & $7,3 \pm 0,50 \mathrm{a}$ & $7-8$ \\
\hline Pupa $\widehat{\sigma}$ & $7,7 \pm 0,71 b$ & $6-9$ \\
\hline Pupa (geral) & $7,5 \pm 0,60$ & $6-9$ \\
\hline Pré-oviposição & $2,6 \pm 1,15$ & $2-4$ \\
\hline Oviposição & $11,3 \pm 2,30$ & $10-14$ \\
\hline Adulto $ᄋ$ & $14,1 \pm 3,00 \mathrm{a}$ & $8-18$ \\
\hline 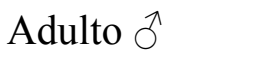 & $13,3 \pm 2,00 \mathrm{a}$ & $9-15$ \\
\hline Adulto (geral) & $13,7 \pm 2,50$ & $8-18$ \\
\hline
\end{tabular}

Para pupas e adultos, médias seguidas pela mesma letra não diferem significativamente pelo teste de Tukey $(\mathrm{P}<0,05)$

variar em uma determinada espécie, dependendo da ação de vários fatores, por exemplo, uma nutrição adequada favorece a ocorrência de menor número de ínstares. Considerando os resultados, as flores de coqueiro constituem uma dieta adequada para 
B. nuciferae, embora esta espécie de planta não seja hospedeira nativa dessa praga. Segundo Bondar (1940a, 1940b) as plantas nativas registradas para B. nuciferae são palmeiras dos gêneros Syagrus [S. coronata (Mart.), S. vagans (Bondar) e S. schizophylla (Mart.)] e Attalea [A. funifera Mart. e A. piassabossu Bondar].

A média da razão de crescimento da espécie foi de 1,761 \pm 0,003 (Tabela 2), ficando dentro dos valores determinados por Dyar (1890) em seu trabalho acerca do número de mudas em diferentes espécies de lepidópteros.

A razão sexual de adultos foi de 0,45 , sendo a relação de 1: 1,2 ( $(+$ : đ) $)$. O período de pré-oviposição (Tabela 1) foi ligeiramente maior ao de B. amydraula (2 \pm 1 dias) criada a $25^{\circ} \mathrm{C}$ de temperatura e $72,5 \pm 2,5 \%$ de umidade relativa (Michael \& Habib, 1971). O número total de ovos por fêmea teve um valor médio de $31,5 \pm 18,3(16,4-$ 49,9). O número de posturas e número de ovos por postura são apresentados na Tabela 3 , onde observa-se que a maior quantidade de ovos correspondeu à primeira postura. $\mathrm{O}$ número total de ovos por fêmea de B. amydraula, criada nas condições já mencionadas, teve uma média de 18,1 \pm 2,9 (11 - 25) (Michael \& Habib, 1971). Provavelmente as espécies de Batrachedra apresentam, em geral, baixa fecundidade. A alta viabilidade $(100 \%)$ das posturas de B. nuciferae talvez constitui uma forma de compensar a baixa fecundidade. Este aspecto junto com o ciclo de vida curto são fatores que favorecem o sucesso da espécie e explicam possivelmente sua abundância nas plantas atacadas.

Tabela 2. Largura da cápsula cefálica e razão de crescimento de B. nuciferae alimentada com pólen de coqueiro $\left(25^{\circ} \mathrm{C}, 60 \% \mathrm{UR}, 12 \mathrm{~h}\right.$ fotofase $)$

\begin{tabular}{cccc}
\hline & \multicolumn{2}{c}{ Largura da cápsula cefálica (mm) } & \\
\cline { 2 - 3 } Instar & Média & Amplitude & Razão de crescimento \\
\hline $1^{0}$ & $0,219 \pm 0,011$ & $0,209-0,243$ & \\
$2^{0}$ & $0,377 \pm 0,016$ & $0,330-0,391$ & 1,721 \\
$3^{0}$ & $0,679 \pm 0,026$ & $0,634-0,729$ & 1,801 \\
\hline
\end{tabular}

Média da razão de crescimento $=1,761 \pm 0,003$ 
Tabela 3. Número de ovos e viabilidade por postura por fêmea de B. nuciferae, alimentada com solução de água e mel $10 \%\left(25^{\circ} \mathrm{C}, 60 \% \mathrm{UR}\right.$, $12 \mathrm{~h}$ fotofase).

\begin{tabular}{cccc}
\hline Postura & Ovos/P & Amplitude & Viabilidade (\%) \\
\hline 1 & $7,3 \pm 3,30$ & $4,6-11$ & 100 \\
2 & $2,5 \pm 2,34$ & $0,3-5$ & 100 \\
3 & $3,6 \pm 1,51$ & $2,5-5,3$ & 100 \\
4 & $3,2 \pm 1,98$ & $1,3-5,2$ & 100 \\
5 & $2,5 \pm 1,80$ & $1-4$ & 100 \\
6 & $3,0 \pm 3,42$ & $0,8-7$ & 100 \\
7 & $2,1 \pm 1,55$ & $1-3,2$ & 100 \\
8 & $2,7 \pm 0,62$ & $2,3-3,2$ & 100 \\
9 & $4,3 \pm 2,36$ & $2,6-6$ & 100 \\
10 & $0,3 \pm 0$ & --- & 100 \\
\hline
\end{tabular}

\section{4 conclusões}

O ciclo de vida de B. nuciferae desde a fase de ovo até a morte do adulto foi em geral de 35,9 dias em condições de $25^{\circ} \mathrm{C}$ de temperatura, $60 \%$ de umidade relativa e 12 horas de fotofase.

As larvas passaram somente por três instares e considera-se que as flores de coqueiro constituem uma dieta natural adequada, embora esta planta não seja uma hospedeira nativa da praga.

O número total de ovos por fêmea teve um valor médio de $31,5 \pm 18,3$; a espécie apresenta relativamente baixa fecundidade; porém, este aspecto pode ser compensado devido à alta viabilidade dos ovos, favorecendo o sucesso da espécie. 


\section{ATRAÇÃO DE BATRACHEDRA NUCIFERAE HODGES (LEPIDOPTERA: COLEOPHORIDAE) COM DIFERENTES COMPRIMENTOS DE ONDAS ELETROMAGNÉTICAS}

\section{Resumo}

Adultos de Batrachedra nuciferae Hodges (Lepidoptera: Coleophoridae), praga do coqueiro (Cocos nucifera L.) no Brasil, foram avaliados em relação a atração com seis luzes fluorescentes de diferentes comprimentos de onda. O estudo foi realizado em laboratório considerando um delineamento experimental inteiramente casualizado com 15 repetições e 20 adultos por repetição. Utilizou-se uma arena com seis tubos encaixados e as seguintes lâmpadas fluorescentes da General Electric: Black Light Blue (F15T8-BLB), Black Light (F15T8-BL), Plant Light (F15T8-PL), Blue (F15T8-B), Gold (F15T8-GO) e Luz do Dia. Os resultados mostram que as luzes ultra violetas (BLB e BL) foram as que atraíram maior numero de insetos, não havendo diferença significativa entre ambas segundo o teste de Tukey a 5\% de probabilidade.

\section{Summary}

Six fluorescent lamps with different long-wave radiation were tested as attractants to adults of Batrachedra nuciferae Hodges (Lepidoptera: Coleophoridae), pest of the coconut palm in Brazil. The experiment was conducted in the laboratory considering an experimental design of completely randomized plots with 15 replicates and 20 moths per replicate. An arena with six attached tubes and the following General Electric lamps were utilized: Black Light (F15T8-BL), Plant Light (F15T8-PL), Blue (F15T8-B), Gold (F15T8-GO) and Daylight. The results showed that the ultraviolet 
lights (BLB and BL) were the most attractants. Statistical difference was not found among the lamps according to the Tukey test at a $5 \%$ of probability.

\subsection{Introdução}

Batrachedra nuciferae Hodges é uma praga da cultura do coqueiro (Cocos nucifera L.) nos estados da Bahia (Bondar, 1940a, 1940b; Hodges, 1966) e São Paulo (Sánchez-Soto \& Nakano, 2002), no Brasil. É registrada também como praga dessa cultura nos estados de Anzoategui, Aragua e Falcón, na Venezuela (Arnal et al., 1998); as larvas atacam as flores masculinas destruindo o pólen, e conseqüentemente reduzem as probabilidades de fecundação das flores femininas e a produção das plantas (Bondar, 1940a, 1940b). A incidência da praga está relacionada com a altura das plantas, registrando-se os maiores ataques em coqueiros anões (Arnal et al., 1998), razão pela qual os problemas com esse inseto no Brasil podem ser maiores no estado de São Paulo, onde tem-se optado pelo plantio do coqueiro anão para a produção de água-de-coco (Tonet \& Pelinson, 1999).

Embora existam recomendações para o controle de pragas do coqueiro no Brasil (Ferreira et al., 1998), tem-se pouco conhecimento sobre o controle delas no estado de São Paulo (Tonet \& Pelinson, 1999). Neste contexto, ainda não existe um método de amostragem que permita avaliar a densidade populacional de B. nuciferae, o qual é fundamental para decidir se a praga deve ou não ser combatida (Gallo et al., 2002). Um método que tem-se mostrado eficiente na captura de insetos com hábitos noturnos, especialmente de mariposas, é o uso de armadilhas luminosas, as quais se baseiam na propriedade de atração da luz sobre os insetos (Silveira Neto et al., 1976; MuirheadThomson, 1991; Nakano \& Leite, 2000).

Visando estabelecer um método de monitoramento da praga, foi realizado o presente trabalho que consistiu em avaliar luzes fluorescentes com diferentes comprimentos de onda na atração de adultos de B. nuciferae. 


\subsection{Material e Métodos}

O estudo foi conduzido utilizando uma arena semelhante à descrita por Botelho et al. (1973). O aparelho consistiu de um recipiente de plástico preto com seis saídas formadas por tubos de papelão preto ( $22 \mathrm{~cm}$ de comprimento $\mathrm{x} 4,5 \mathrm{~cm}$ de diâmetro) cujo extremo tinha um funil de plástico transparente $(2 \mathrm{~cm}$ de diâmetro). No fundo do recipiente havia um orifício central onde era inserido um pequeno frasco de plástico preto $(5 \mathrm{~cm}$ de altura $\times 3 \mathrm{~cm}$ de diâmetro) que era utilizado para confinar os insetos. $\mathrm{Na}$ parte inferior desse frasco havia um orifício vedado com um pedaço de tecido de malha para circulação do ar, e na parte superior havia outro orifício ( $9 \mathrm{~mm}$ de diâmetro) por onde eram introduzidos os insetos (Figura 1).

Foram utilizadas lâmpadas de 15 watt (General Electric) com luzes fluorescentes de diferentes comprimentos de onda: Black Light Blue (F15T8-BLB), Black Light (F15T8-BL), Plant Light (F15T8-PL), Blue (F15T8-B), Gold (F15T8-GO) e Luz do Dia. Foram realizadas 15 repetições utilizando 20 adultos por repetição. Em cada repetição as lâmpadas eram trocadas de posição de forma aleatória. Os ensaios foram conduzidos em quarto escuro entre as 19:00 e 20:00 horas, realizando-se uma repetição por dia. Os insetos utilizados eram de ambos os sexos e diferentes idades, e procediam de criação com flores de coqueiro em laboratório.

$\mathrm{O}$ teste foi feito da seguinte maneira: no extremo de cada tubo foi colocado um saquinho de plástico transparente para que os insetos atraídos ficassem presos após passar pelo funil; posteriormente a arena era colocada sobre uma base (caixa de papelão) e as lâmpadas, já fixas em uma base de madeira, eram colocadas em posição vertical próxima das extremidades dos tubos. A seguir, no orifício do fundo da arena era inserido o frasco contendo os insetos, que foram introduzidos previamente com ajuda de um aspirador manual. Os insetos ficavam presos no frasco ao colocar um chumaço de algodão no orifício. Após 30 minutos, as lâmpadas eram acesas, o chumaço de algodão do frasco era retirado para permitir a saída dos adultos e imediatamente era colocada a tampa da arena. As lâmpadas ficavam acesas por dez minutos, procedendo-se posteriormente à contagem dos insetos atraídos (Figura 2). 


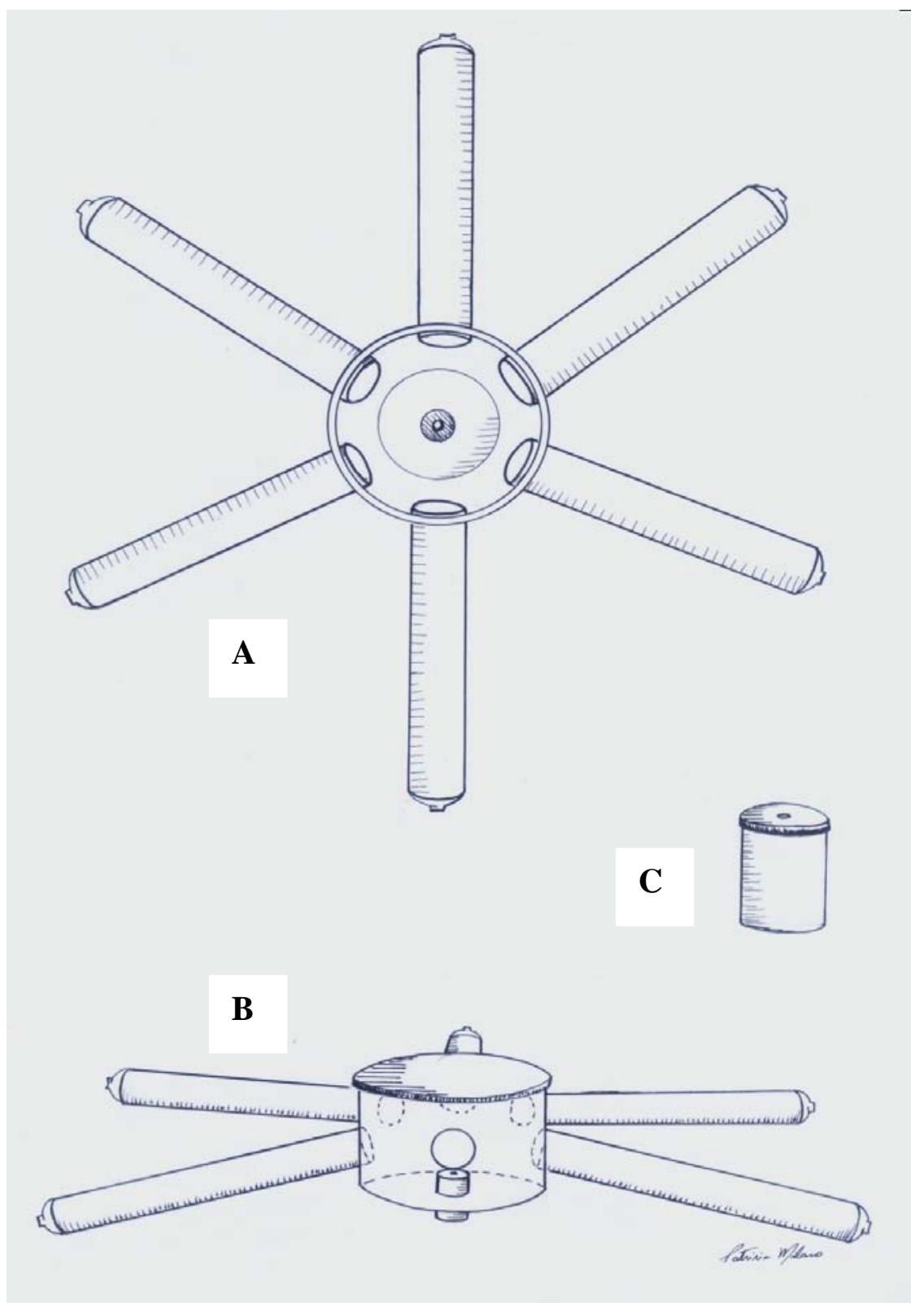

Figura 1 - Arena utilizada no estudo de atração de adultos de B. nuciferae com luzes de diferentes comprimentos de onda. A) Vista superior, B) vista lateral e C) frasco para confinar insetos 


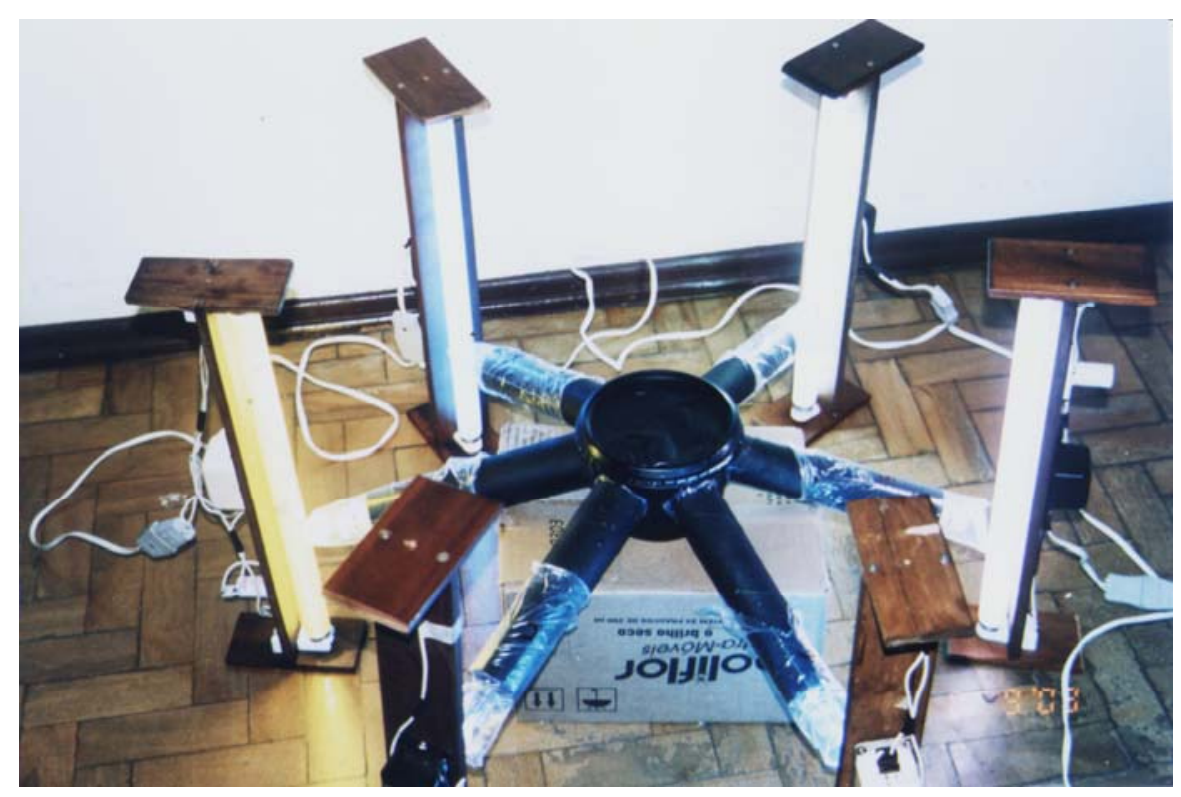

Figura 2 - Arena e lâmpadas utilizadas no estudo de atração de adultos de B. nuciferae com luzes de diferentes comprimentos de onda

O delineamento experimental foi o inteiramente casualizado. Os dados foram submetidos à análise de variância, sendo as médias comparadas pelo teste de Tukey, a $5 \%$ de probabilidade.

\subsection{Resultados e Discussão}

A luz que atraiu maior número de adultos foi a Black Light Blue, seguida pela Black Light, ambas ultra violetas, entre as quais não houve diferença estatística significativa (Tabela 1). De acordo com Silveira Neto et al. (1976), os insetos apresentam $100 \%$ de resposta aos comprimentos de onda ao redor de $365 \mathrm{~m} \mu$, valor que fica dentro da faixa de luz ultra violeta, razão pela qual acredita-se que lâmpadas com este tipo de luz devem ser mais eficientes na coleta de insetos de modo geral. Com relação a lepidópteros, a maioria das mariposas são atraídas por esse tipo de luz (Nakano 
\& Leite, 2000), que é a mais usada em armadilhas luminosas (Muirhead-Thomson, 1991), sendo utilizada no Brasil para coletas, levantamentos populacionais e controle de pragas (Gallo et al., 2002).

A luz que atraiu menor numero de insetos foi a Gold, que é um tipo de luz amarela; porém, não apresentou diferença significativa com relação às luzes Blue, Luz do Dia, Plant Light e Black Light (Tabela 1). De acordo com Nakano \& Leite (2000), a lâmpada amarela da GE pode servir para espantar insetos e não para atrai-los. Estudos feitos utilizando uma arena similar revelaram que a luz Gold foi a menos atrativa para adultos da mosca doméstica, Musca domestica (L.) (Diptera: Muscidae) (Botelho et al., 1973), enquanto adultos do bicho-furão-dos-citros, Ecdytolopha aurantiana (Lima) (Lepidoptera: Tortricidae), não foram atraídos pela luz amarela (Garcia, 1998).

Embora as luzes ultra violetas (BLB e BL) fossem as mais atrativas para os adultos de $B$. nuciferae, as porcentagens de atração foram baixas (Tabela 1) considerando o total de insetos utilizados no estudo (300). Alguns fatores que talvez influíram na baixa porcentagem de atração foram possivelmente o curto período de

Tabela 1. Número de adultos de B. nuciferae atraídos por lâmpadas fluorescentes com luzes de diferentes comprimentos de onda

\begin{tabular}{lccc}
\hline \multirow{2}{*}{ Lâmpada } & \multicolumn{3}{c}{ Insetos atraídos } \\
\cline { 2 - 4 } & Total & Média & $\%$ \\
\hline Black Light Blue & 35 & $2,33 \mathrm{a}$ & 11,66 \\
Black Light & 26 & $1,73 \mathrm{ab}$ & 8,66 \\
Plant Light & 12 & $0,80 \mathrm{~b}$ & 4,00 \\
Luz do Dia & 11 & $0,73 \mathrm{~b}$ & 3,66 \\
Blue & 11 & $0,73 \mathrm{~b}$ & 3,66 \\
Gold & 07 & $0,46 \mathrm{~b}$ & 2,33 \\
\hline
\end{tabular}

Media seguida pela mesma letra, na vertical, não diferem estatisticamente entre si pelo teste de Tukey $(\mathrm{P} \leq 0,05)$ 
tempo em que as lâmpadas ficaram ligadas (10 minutos); idade dos insetos, onde os mais velhos possivelmente reagem menos, bem como possível estresse devido às condições do próprio experimento. Por essa razão sugerem-se estudos em campo utilizando armadilhas com luz ultravioleta.

\subsection{Conclusões}

As luzes ultravioletas Black Light Blue e Black Light foram as que atraíram maior número de adultos de B. nuciferae, razão pela qual acredita-se que este tipo de luz seja a mais eficiente na atração desse inseto em campo.

Os resultados com esse tipo de luz amplia a possibilidade de utilizar armadilhas luminosas para monitorar as populações dessa praga em campo. 


\section{CONCLUSÕES}

A morfologia externa de B. nuciferae apresenta semelhanças com a de outras espécies do gênero nas quatro fases estudadas: ovo, larval, pupal e adulta.

As descrições e desenhos do ovo, larva, pupas e adultos seriam úteis em trabalhos futuros para a identificação da praga, porém, sugere-se sempre confirmar a identificação mediante estudo das genitálias consultando a descrição original da espécie.

A separação de sexos de B. nuciferae pode ser realizada na fase pupal e adulta considerandos as diferenças morfológicas no extremo do abdômen em ambos os sexos.

O mapa de cerdas da larva de último ínstar é o mais completo dentro do gênero Batrachedra, onde são consideradas pela primeira vez as cerdas microscópicas (propioceptores) e os poros da cabeça.

$O$ ciclo de vida de $B$. nuciferae foi relativamente curto considerando as condições do experimento, de modo que nas régios produtoras de coco no Brasil o inseto poderia apresentar várias gerações ao ano.

As flores de coqueiro constituem uma dieta natural adequada para as larvas de $B$. nuciferae, podendo isto explicar, pelo menos parcialmente, a abundância desse inseto nas plantas atacadas.

A espécie apresenta baixa fecundidade, e pelo contrario alta viabilidade de ovos.

As luzes ultravioletas foram mais atrativas para os adultos de B. nuciferae, o que concorda com a literatura existente sobre a importância deste tipo de luz na atração de mariposas, e amplia a possibilidade de utilizar armadilhas luminosas para o monitoramento das populações dessa praga. 


\section{REFERENCIAS BIBLIOGRÁFICAS}

ARAGÃO, W.M.; SIQUIERA, E.R. de; RIBEIRO, F.E.; TUPINAMBÁ, E.A. Melhoramento do coqueiro variedades e híbridos. In: SÃO JOSÉ, A.R.; SOUZA, I.V.B.; MOURA, J.I.L.; REBOUÇAS, T.N.H. (Ed.). Coco: produção e mercado. Vitória da Conquista: DFZ/UESB, 1999, cap.5, p.44-68.

ARNAL, E.; CLAVIJO, J.; SOTO, E.; RAMOS, F. Batrachedra nuciferae Hodges, 1966 (Lepidoptera: Momphidae) nueva plaga del cocotero en Venezuela. Boletín de Entomología Venezolana, v.13, p. 69-71, 1998.

BOLOV, A.P.; SINEV, S.Y. Batrachedra pinicolella Dup. (Lepidoptera, Batrachedridae), a pest of conifers in Kabardino, Balkaria. Entomological Review, v. 69, p.16-20, 1990.

BONDAR, G. Insetos nocivos e moléstias do coqueiro (Cocos nucifera) no Brasil. Bahia: Tipografia Naval, 1940a, 160p.

BONDAR, G. Notas entomológicas da Bahia, V. Revista de Entomologia, v. 11, p.199214, 1940b.

BOTELHO, P.S.M.; SILVEIRA NETO, S.; SALLES, L.A.B.; BARBIN, D.; BORGES, C.G. Teste de atração de Musca domestica L. com luzes de diferentes comprimentos de onda. O Solo, v. 65, p.42-45, 1973. 
BRADLEY, J.D. The ditrysian 'microlepidoptera' superfamilies. In: BETTS, C.R. (Ed.). CIE guides to insects of importance to man 1. Lepidoptera. London: CAB/BMNH, 1989, p.77-132.

CUENCA, M.A.G. Importância econômica do coqueiro. In: FERREIRA, J.M.S.; WARWICK, D.R.N.; SIQUEIRA, L.A. (Ed.) A cultura do coqueiro no Brasil. Brasília: EMBRAPA, 1998. cap.1, p.17-56.

DYAR, H.G. The number of molts of lepidopterous larvae. Psyche, v.5, p.420-422, 1890.

FERREIRA, J.M.S.; LIMA, M.F.; SANTANA, D.L.Q.; MOURA, J.I.L. Pragas do coqueiro. In: SOBRINHO, R.B.; CARDOSO, J.E.; FREIRE, F.C.O. (Ed.) Pragas de fruteiras tropicais de importância agroindustrial. Brasília: EMBRAPA, 1998a. cap.3, p. 81-118.

FERREIRA, J.M.S.; LIMA, M.F.; SANTANA, D.L.Q.; MOURA, J.I.L.; SOUZA, L.A. Pragas do Coqueiro. In: FERREIRA, J.M.S.; WARWICK, D.R.N.; SIQUEIRA, L.A. (Ed.). A Cultura do Coqueiro no Brasil. Brasília: EMBRAPA, 1998b. cap.8 , p. 189-267.

GALLO, D.; NAKANO, O.; NETO, S.S.; CARVALHO, R.P.L.; BATISTA, G.C.; FILHO, E.B.; PARRA, J.R.P.; ZUCCHI, R.A.; ALVES, S.B.; VENDRAMIM, J.D.; MARCHINI, L.C.; LOPES, J.R.S.; OMOTO, C. Entomologia Agrícola. Piracicaba: FEALQ, 2002, 920p. 
GARCIA, M.S. Bioecologia e potencial de controle biológico de Ecdytolopha aurantiana (Lima, 1927) (Lepidoptera: Tortricidae), o bicho-furão-dos-citros, através de Trichogramma pretiosum Riley, 1879. Piracicaba, 1998. 118p. Tese (Doutorado) - Escola Superior de Agricultura "Luiz de Queiroz”, Universidade de São Paulo.

HINTON, H.E. On the homology and nomenclature of the setae of lepidopterous larvae, with some notes on the phylogeny of the Lepidoptera. Transaction of the Royal Entomological Society of London, v. 97, p.1-37, 1946.

HODGES, R.W. Review of New World species of Batrachedra, with description of three new genera (Lepidoptera: Gelechioidea). Transaction of the American Entomological Society, v. 92, p.585-651, 1966.

HOLLOWAY, J.D.; BRADLEY, J.D. Introduction. In: BETTS, C.R. (Ed.). CIE guides to insects of importance to man 1. Lepidoptera. London: CAB/BMNH, 1987. cap.1, p. 1-22.

KIMBER, I. Momphidae: Batrachedrinae. <http://cgi.ukmoths.force9.co.uk/cgibin/show.pl?bf=8780>. (02 jan. 2002).

LEVER, R.J.A.W. Pests of the coconut palm. Rome: FAO, 1969. 190p.

MEYRICK, E. Exotic Microlepidoptera, v.2, p. 577-608, 1922.

MICHAEL, I.F.; HABIB, A.A. Biology of Batrachedra amydraula Meyr., the lesser date moth. Date Growers Institute Report, v.48, p.6-8, 1971. 
MOURA, J.I.L. Manejo integrado das pragas do coqueiro. In: SÃO JOSÉ, A.B.; SOUZA, I.V.B.; MOURA, J.I.L.; REBOUÇAS, T.N.H. (Ed.). Coco: produção e mercado. Bahia: UESB, 1999. cap.11, p. 131-150.

MOSHER, E. Lepidoptera pupae: five collected works on the pupae of North American Lepidoptera. Michigan: ERS, 1969. 323p.

MUIRHEAD-THOMSON, R.C. Trap Responses of Flying Insects. London: Academic Press, 1991.287p.

NAKANO, O.; LEITE, C.A. Armadilhas para Insetos: Pragas Agrícolas e Domésticas. Piracicaba: FEALQ, 2000. 76p.

NEL, J. Some new microlepidoptera for the french fauna (Lepidoptera Tineidae, Elachistidae, Batrachedridae, Scythrididae and Cosmopterigidae). Alexanor, v.20, n.7, p.419-424, 1998.

NYE, I.W.B.; FLETCHER, D.S. The generic names of moths of the world. London: Natural History Museum Publications, 1991. 368p. v.6 (Microlepidoptera).

PARRA, J.R.P. Técnicas de criação de insetos para programas de controle biológico. Piracicaba: ESALQ/FEALQ, 2001. 134p.

PARRA, J.R.P.; HADAD, M.L. Determinação do número de instares de insetos. Piracicaba: FEALQ, 1989. 49p.

PIRES, M.M.; SÃO JOSÉ, A.R.; RUFINO, J.L. dos SANTOS; BRAGA, M.J. Aspectos econômicos da cultura de coco no Brasil. In: SÃO JOSÉ, A.R.; SOUZA, I.V.B.; MOURA, J.I.L.; REBOUÇAS, T.N.H. (Ed.). Coco: produção e mercado. Vitória da Conquista: DFZ/UESB, 1999. p.7-19. 
SÁNCHEZ-SOTO, S.; NAKANO, O. Ocorrência de Batrachedra nuciferae Hodges (Lepidoptera: Coleophoridae) no Estado de São Paulo. Neotropical Entomology, v.31, p.657-658, 2002.

SILVEIRA NETO, S.; NAKANO, O.; BARBIN, D.; VILLA NOVA, N.A. Manual de Ecologia dos Insetos. São Paulo: CERES, 1976. 419p.

SINEV, S.Y. New and little-known species of narrow-winged moths (Lepidoptera: Stathmopodidae, Batrachedridae, Momphidae, Blastodacnidae, Cosmopterigidae) from Primorsk territory. Proceedings of the Zoological Institute, v.251, p.17-38, 1993.

STEHR, F.W. Oecophoridae (Gelechioidea). In: STEHR, F.W. (Ed.). Immature insects. Dubuque: Kendall/Hunt, 1987a, v.1, cap.26, p.379-383.

STEHR, F.W. Coleophoridae (Gelechioidea). In: STEHR, F.W. (Ed.). Immature insects. Dubuque: Kendall/Hunt, 1987b, v.1, cap.26, p.387-388.

STEHR, F.W. Order Lepidoptera. In: STEHR, F.W. (Ed.). Immature insects. Dubuque: Kendall/Hunt, 1987c, v.1, cap.26, p.288-305.

STEHR, F.W.; MARTINAT, P.J. Lepidoptera, key to families of larvae. In: STEHR, F.W. (Ed.). Immature insects. Dubuque: Kendall/Hunt, 1987, v.1, cap.26, p.306340 .

TONET, R.M.; PELINSON, G.J.B. A situação da cultura do coqueiro no Estado de São Paulo. In: SÃO JOSÉ, A.B.; SOUZA, I.V.B.; MOURA, J.I.L.; REBOUÇAS, T.N.H. (Ed.). Coco: produção e mercado. Bahia: UESB, 1999. cap.19, p. 222-238. 
VELEZ-ANGEL, R. Ciclo de vida y hábitos del pasador de las hojas del fique, Batrachedra rixator Hodges, en Antioquia. Revista Gallescencia, v.1, n.1, p.13-24, 1981.

VILARDEBO, A. Parasites et maladies. In: MUNIER, P. (Ed.). Le palmier-dattier. Paris: G.-P. Maisonneuve \& Larose, 1973. cap.4, p.67-108.

ZHANG, B.C. Index of economically important Lepidoptera. Wallingford: CAB International, 1994. 599p. 